IZA DP No. 6342

Positional Concerns through the Life Cycle:

Evidence from Subjective Well-Being Data and Survey Experiments

Alpaslan Akay

Peter Martinsson

February 2012 


\title{
Positional Concerns through the Life Cycle: Evidence from Subjective Well-Being Data and Survey Experiments
}

\author{
Alpaslan Akay \\ IZA \\ Peter Martinsson \\ University of Gothenburg
}

Discussion Paper No. 6342

February 2012

IZA

P.O. Box 7240

53072 Bonn

Germany

Phone: $+49-228-3894-0$

Fax: +49-228-3894-180

E-mail: iza@iza.org

\begin{abstract}
Any opinions expressed here are those of the author(s) and not those of IZA. Research published in this series may include views on policy, but the institute itself takes no institutional policy positions.

The Institute for the Study of Labor (IZA) in Bonn is a local and virtual international research center and a place of communication between science, politics and business. IZA is an independent nonprofit organization supported by Deutsche Post Foundation. The center is associated with the University of Bonn and offers a stimulating research environment through its international network, workshops and conferences, data service, project support, research visits and doctoral program. IZA engages in (i) original and internationally competitive research in all fields of labor economics, (ii) development of policy concepts, and (iii) dissemination of research results and concepts to the interested public.
\end{abstract}

IZA Discussion Papers often represent preliminary work and are circulated to encourage discussion. Citation of such a paper should account for its provisional character. A revised version may be available directly from the author. 


\section{ABSTRACT}

\section{Positional Concerns through the Life Cycle: Evidence from Subjective Well-Being Data and Survey Experiments ${ }^{*}$}

This paper uses both subjective well-being and survey experimental data to analyze how people's positional concerns regarding income and goods vary with age. The subjective wellbeing approach is mainly based on German panel data for the period 1984-2009 (German Socio-Economic Panel), while the survey experimental approach is based on a tailor-made experimental design conducted among Swedish adults. Our analysis suggests that the degree of positional concerns is not homogenous across the life cycle. Our different analytical approaches show a robust life cycle pattern of positional concerns: young people experience no or a low degree of positional concerns, yet the level of concerns for income increases gradually and significantly with age. The results also differ across goods: while car consumption is similar to income, the positional concern for leisure time decreases through the life cycle.

\section{JEL Classification: $\quad$ C90, D63}

Keywords: positional concerns, life cycle, subjective well-being, survey experiment

Corresponding author:

Alpaslan Akay

IZA

P.O. Box 7240

53072 Bonn

Germany

E-mail: akay@iza.org

\footnotetext{
* Financial support from the Swedish Research Council (Vetenskapsrådet) is gratefully acknowledged. We would like to thank Andrew Oswald, Claudia Senik, Uri Haffetz, and Olivier Bargain for helpful and constructive comments.
} 


\section{Introduction}

The Easterlin Paradox is perhaps one of the most influential observations of contemporary economics (Easterlin, 1974; updated in 1995). The paradox states that there has been substantial growth in the real income levels of Western countries over the last fifty years without hardly any corresponding increases in the well-being (measured as "happiness" or "life satisfaction") of individuals even though the income and well-being are highly positively correlated in each cross section. A potential explanation of this paradox is that the utility derived from income or consumption of a good depends not solely on the absolute amount of income or the good consumed but also depends on the relative amount of income or the good consumed compared to the good consumed by other individuals, i.e., positional or relative concerns (Brickman and Campbell, 1971; Easterlin, 1974; 1995; Frank, 1985; Clark and Oswald, 1996; Ferrer-i-Carbonell, 2005; Clark et al., 2008). ${ }^{1}$ Although this idea is not new, as it has long have been discussed by many thinkers in the past (e.g., Adam Smith, Karl Marx, Alfred Marshall, Thorstein Veblen, Arthur Pigou, and Tibor Scitovsky), it has only very recently been revisited and empirically tested using both subjective well-being data (e.g., Frank, 1985; Clark and Oswald, 1996; Senik, 2004, 2007; Ferrer-i-Carbonell, 2005; Clark et al, 2008) and tailor-made survey experiments (e.g., Solnick and Hemenway, 1998, 2007; Johansson-Stenman et al., 2002; Alpizar et al., 2005; Akay et al., 2011). A consistent finding across these studies is that people do have positional concerns. Income levels of "relevant" others negatively affect people's utility in the Western developed countries (McBride, 2001; Luttmer, 2005; Ferrer-i-Carbonell, 2005; Clark et al., 2008). The results are more mixed in the developing and transition country context (Ravallion and Lokshin, 2000, 2002; Senik, 2004, 2005, 2007; Kingdon and Knight, 2007; Knight et al., 2009; Bookwalter and Dalenberg, 2010; Caporale et al., 2009; Akay and Martinsson, 2011). Today there is a growing literature that aims to understand the implications of positional concerns on individual welfare (e.g., Frank, 1985), but also on many

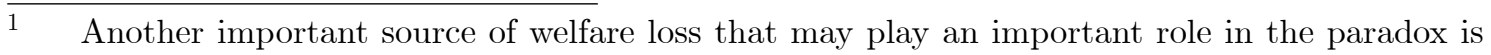
that individuals adapt to income levels over time (Brickman and Campbell, 1971; Stutzer, 2004; DiTella et al., 2011). 
other crucial issues in economics, e.g., saving and investment (Abel, 1990; 2005), economic growth (Carroll et al. 1997; Easterlin, 1995; Oswald, 1997; Stevenson and Wolfers, 2008), labor supply (Neumark and Postlewaite, 1998; Woittiez and Kapteyn, 1998; Park, 2006), migration (Knight et al., 2007; Akay et al., 2011), and optimal taxation (Boskin and Sheshinski, 1978; Frank, 1985; Ljungqvist and Uhlig, 2000; Aronsson and Johansson-Stenman, 2008).

The present paper contributes to the empirical literature on positional concerns by examining the life cycle patterns of utility generated by positional concerns. The previous studies have only focused on identifying an average effect of positional concerns representing the degree of positionality preferences in a population, either for income levels per se or for the levels of some other consumption goods such as cars, holidays, and working hours (e.g., Clark and Oswald, 1996; Senik, 2005; Ferrer-i-Carbonell, 2005; Solnick and Hemenway, 1998, 2007; Johansson-Stenman et al., 2002; Carlsson et al., 2007). In other words, the previous studies implicitly assume that the positional concerns of individuals are homogeneous across the life cycle. People do experience various phases in their lives in terms of, e.g., income level, type of job, and marital status (Levinson, 1977; Levinson et al., 1978). Given these changes in life, there are reasons to believe that there is substantial heterogeneity in the degree of positional concerns across the life span of an individual, and understanding this across age may reveal important insights.

There may be various other reasons as well behind the heterogeneity in positional concerns across age. One important factor is that the composition of consumption goods could change as a person gets older. Recent research suggests that the degree of positional concerns differs substantially across goods for the average person and age. For example, people have a higher degree of positional concern for income and car consumption, than for working hours and number of vacation days (e.g., Frank, 1985; Solnick and Hemenway, 1998, 2007; Carlsson et al., 2007). However, people may also value the same good differently across age: while they give more or less importance to quantity of consumption in some periods, they may give more or less importance to other aspects such as ecological or moral values during different periods of their lives. Moreover, there may be a birth-cohort effect on the income or 
consumption comparisons since at any given point in time people born in different cohorts coexist in the same society (Clark et al., 1996; Clark, 2007; Blanchflower and Oswald, 2008).

Measuring positional concerns is an elusive issue. There are two major approaches to testing positional concerns, and we employ both in this paper. The first approach uses a subjective well-being (SWB) dataset based on a "life satisfaction" measure. To test positional concerns with a SWB approach, regression analysis has been used in the literature. In the regression analysis, "relative income", i.e., the average income of the "reference" or "comparison group", is controlled for together with the absolute level of income and many other observed (and unobserved) individual characteristics. The sign and significance of the relative income parameter are then used as an indicator for the average degree of positional concern among the population of interest. The general conclusion is that the relative income effect is negative and highly significant in both and economic and statistical sense, implying that positional concerns on average result in welfare loss (e.g., Clark and Oswald, 1996; McBride, 2001; Ferrer-i-Carbonell, 2005; Luttmer, 2005; Clark et al., 2008). One weakness of the SWB approach is that the definition of the "reference group", i.e., the "relevant others", is unknown a priori. A "reference group" is a highly complicated concept (e.g., Runciman, 1966). Most studies use ad hoc definitions of reference groups based on spatial orbits of socio-demographic and economic proximities (Clark and Oswald, 1996; Ferrer-i-Carbonell, 2005; Senik, 2009; Clark and Senik, 2010). One way to approximate is to directly ask individuals and then elicit temporal reference groups. However, such information is not routinely collected. Yet Senik and Clark (2010) conducted a study based on direct elicitation of reference groups and found very similar results to the methodology based on ad hoc definitions of reference groups (see, e.g., Ferrer-i-Carbonell, 2005). It is reasonable to assume that the reference group differs from one individual to another, but without any a priori information it has to be constructed using some ad hoc rules. Moreover, the rule to determine the reference group might also change with age depending on the socio-economic circumstances over the life cycle. In order to account for changing reference group compositions across age, a long panel dataset with re- 
peated SWB observations should be available. To address this issue properly, we use the longest panel dataset, i.e., German Socio Economic Panel (GSOEP), available in the happiness literature, together with the British Household Panel Survey (BHPS). Moreover, we test many different reference groups and conduct a comprehensive robustness analysis of our benchmark results.

The second approach that we use is based on a tailored survey experiment designed to explicitly identify the degree to which individuals care about absolute and relative income or consumption of different consumption goods. The empirical results based on this approach suggest that people do have positional concerns and that the degree of concern differs across consumption goods (e.g., JohanssonStenman et al., 2002; Solnick and Hemenway, 1998, 2007). The approach uses stated preferences, and thus the survey experiment has to be designed. For this purpose, a utility function is defined, which is used to explicitly parameterize positional concerns, for example the income levels in the experiment. Subjects are asked to make repeated choices between two alternatives, which vary in own income and income of others. Thus, it is then possible to estimate the relative impact of absolute and relative income on utility. One of the most important advantages of this approach is that it does not suffer from the problem of unknown or switching reference groups (or both) over the life cycle, since the reference groups are explicitly stated in the survey experiment. Our survey experiment uses, to our knowledge, the largest nonstudent sample of subjects by including responses from the general Swedish adult population. This allows us to identify whether positional concerns vary with age.

To our knowledge this is the first comprehensive study of its kind in the literature including both long panels of SWB datasets and survey experiments to examine the life cycle patters of positional concerns for income per se and for other consumption goods. The closest study to the current paper is by FitzRoy et al. (2011). Their paper examines the relative concerns of young and old people using only a cross section of SWB datasets. We confirm the previous results reported in the literature that people do have concerns for positionality with both approaches used in the paper, and that relative concern increases by age as in FitzRoy et al. (2011). A detailed analysis, based on long panel datasets and more precise reference groups, 
suggests solid evidence that positional concerns are not homogenous along the life span of an individual with complicated patterns. There are clearly different phases in an individual's life, each with different positional concerns. The main pattern is that younger people are found to be less affected by positional concerns, or as in the SWB approach, they may even be positively affected by their relative income. The latter may be interpreted as a signal effect (or "tunnel effect" as coined by Hirschman and Rothschild, 1973), where a high level of income in a reference group works as a signal about the future income level of young people in general, leading to high well-being or less welfare loss. The effect of positional concerns is relatively stable and slowly increasing during middle age of the individuals, i.e., people experience a gradually and slowly increasing welfare loss due to positional concerns during middle age. However, the effect of positional concerns is larger and larger as people get older.

In our analyses, we find evidence that people's positional concerns are not the same for different consumption goods, and the life cycle pattern of positional concerns also differs depending on the type of good. Our survey experimental evidence suggests that people are more positional for income and car consumption than for working hours. Moreover, people's positional concerns for income and car consumption increase with age, whereas the opposite is found for working hours. The result of increasing positional concerns over the life cycle is only partially explained by the birth cohort effects. The further results in the paper also suggest that the very similar positionality patterns for men and women across age. The results are not sensitive to the reference group definition. One of the other important findings of this paper is that the effect of absolute income on SWB is also heterogeneous across age. Overall, this result implies that the marginal utility of income is not the same for the same level of increase in income across age. The marginal utility of income is the highest around age 40, and there is also great deal of utility loss due to positional concerns around the same age. This result is one of the important findings that may explain why the relationship between age and SWB is U-shaped and reaches its minimum point around age 40 (Clark et al., 1996; Clark, 1997; Blanchflower and Oswald, 2008). 
The remaining part of the paper is organized as follows. The next section will present results from the SWB approach, including the panel dataset, results of lifecycle positional concerns, and a comprehensive robustness check based on various definitions of reference groups. We also examine life-cycle differences by gender as well as the impact of absolute income over the life span. Section 3 presents the results from the tailored survey experimental approach, including the experimental design and the results of the experiment based on non-parametric estimators. Finally, Section 4 discusses the results and concludes the paper.

\section{Evidence from Subjective Well-Being Data}

\subsection{The data}

Our main dataset when investigating the relationship between SWB and concerns for relative income is the German Socio Economic Panel dataset (GSOEP), which is one of the most widely used microeconomic panel datasets in the SWB literature (e.g., Winkelmann and Winkelmann, 1998; van Praag et al., 2003; Frijters et al., 2004). ${ }^{2}$ This annual panel survey was first launched in 1984 in West Germany among 12,000 households, which have been followed since then. The sample has been extended over the years, most notably by including about 2,000 East German households in 1990. The SWB measure is obtained by asking the subjects "How satisfied are you at present with your life as a whole?" having them respond using an ordinal 11-point scale from 0 to 10 , where 0 means "completely dissatisfied" and 10 means "completely satisfied." In our analyses, we use the surveys from 1984 to 2009 and restrict the sample in the analyses to only include the native population to avoid the possible confounding effect of migration. We also exclude individuals who are younger than 20 or older than 80 . Our analyses contain around 150,000 observations, which comprise a sub-sample of the entire GSOEP dataset. However, our sample includes people of different ages at each point in time, allowing us to test for birth cohort effects by comparing individuals of the same age from different

$\overline{2} \quad$ We also use the British Household Panel Survey (BHPS) dataset to check the sensitivity of the results. 
time periods.

In the econometric specification, we follow up the main approach in the analyses of SWB and regress income and other socio-economic factors such as health, marital status and having children on people's SWB (van praag and Ferrer-i-Carbonell, 2008). In our regression analyses, we control for both absolute and relative income (as described below), where income is entered in the analyses as the logarithm of the family income from all sources including government transfers. ${ }^{3}$ We control for labor force status by using an indicator variable and the logarithm of weekly working hours and of household size. An important issue is the birth cohort effects. We have a panel dataset that can be used to identify age and cohort effects. Following Clark (2007), we use birth cohorts as indicator variables for 5-year birth intervals starting from the beginning of the last century. ${ }^{4}$ In order to control for the time trend on SWB, we also control for year dummies for each period in the panel dataset.

\subsection{Framework and econometric methods}

Given the ordinal nature of the SWB measure, the ordered probit specification would be an appropriate regression. Therefore, our default model specification considers SWB as latent:

$$
\begin{aligned}
S W B_{i t}^{*} & =\beta_{\text {absolute }} \log \left(y_{i t}\right)+\beta_{\text {relative }} \log \left(y_{j}^{r}\right)+\gamma x_{i t}+u_{i t} \\
u_{i t} & =\alpha_{i}+\tau_{t}+\epsilon_{i t}
\end{aligned}
$$

where $S W B_{i t}$ is the self-reported SWB of individual $i$ in year $t$ reported on an ordinal scale; $y_{i t}$ is absolute income of individual $i ; y_{j}^{r}$ is the average income of reference group $j$, i.e., relative income, defined as $y_{j}^{r}=1 /\left(N_{j}-1\right) \sum_{s=1}^{N_{j}-1} y_{s}^{r}$ (where $N_{j}$ is the number of individuals who are in the $j$ th reference group); $\beta_{\text {absolute }}$ and $\beta_{\text {relative }}$ are the parameters for the absolute and relative income to be estimated; $x_{i t}$

3 We follow the variable definitions commonly used in the literature (see, e.g., Ferrer-i-Carbonell, 2005).

4 There are a total of 14 birth cohorts in our analysis: one for pre-1920, twelve for the period 1920-1985, and one for post-1985. 
is a vector of socio-demographic characteristics, such as age, sex, and marital and health status; and $\gamma$ is a vector of estimated parameters of the socio-demographic variables. The error terms $u_{i t}$ are split into various components: $\alpha_{i}$ is the unobserved individual effects; $\tau_{t}$ is time trend controlled by year dummies; and $\epsilon_{i t}$ denotes the error terms that are assumed to be normally distributed with zero mean and unit variance for identification. However, in the estimations, we apply a number of different specifications to test the robustness of our result by also running OLS, linear fixed, and random effects models.

We expect absolute income affects SWB positively $\left(\beta_{\text {absolute }}>0\right)$, implying a higher income is associated with a higher welfare. However, the effect of relative income on SWB is a priori undetermined. It could be positive or negative. The relative concerns may affect SWB negatively $\left(\beta_{\text {relative }}<0\right)$ implying a reduction in the SWB due to income comparisons. We will interpret a negative relative income effect as "status-effect" of the income position. However, the relative income could also affect the utility positively $\left(\beta_{\text {relative }}>0\right)$ implying an increase in the SWB. In this case a higher income of the similar others may work as information about the future income levels of individuals and leads to develop positive expectations about the future prosperity. We will interpret this as a "signal" or "demonstration" effect as used in Hirschman and Rothschild (1973) or Senik (2005). ${ }^{5}$

Our purpose is to identify the life-cycle patterns of positional concerns. To be able to calculate the relative income effect across age, we use an interaction model.

5 The other interpretation of a positive relative income effect is altruistic preferences. However, this interpretation seems likely to be possible only in poor and highly cooperative societies such as rural Chinese villages, as found in Kingdon and Knight (2007). We interpret a positive relative income effect as a signal-effect as in the case of transition economies (e.g., Ravillon and Lokshin, 2000; Senik, 2005). 
Thus, the SWB function that we estimate reads as follows:

$$
\begin{aligned}
S W B_{i t}^{*} & =\beta_{\text {absolute }} \log \left(y_{\text {it }}\right)+\beta_{\text {relative }} \log \left(y_{j}^{r}\right) \\
& +\sum_{s=2}^{C} \beta_{\text {age }, s} \text { age } \\
& +\sum_{s=2}^{C} \beta_{\text {absolute }, s} \log \left(y_{i t}^{s}\right) \times a g e_{s} \\
& +\sum_{s=2}^{C} \beta_{\text {relative }, s} \log \left(y_{j}^{r, s}\right) \times \text { age }_{s} \\
& +\gamma x_{i t}+\alpha_{i}+\tau_{t}+\epsilon_{i t}
\end{aligned}
$$

The only difference between (2) compared to (1) is the interaction terms. In total, there are $C$ age groups and thus we will be able to estimate $C-1$ relative income parameters for those age categories. Since the sample size in GSOEP is very large, it is possible to estimate a relative income parameter for every age starting from 20. However, for the sake of robustness of results we do not split data into very small cells. Instead, we use dummy variables for only $C=6$ age groups as $[20,30)$, $[30,40),[40,50),[50,60),[60,70)$ and $[70,80]$, where the youngest group is the omitted category. We later estimate both the absolute income and relative income effects occurring in an age category $\left(\widehat{\beta}_{\text {absolute }, s}\right.$ and $\left.\widehat{\beta}_{\text {relative }, s}\right)$.

Defining reference groups: To investigate the degree of positional concerns accurately, it is important that each individual is compared to her true reference groups. However, the exact reference group of an individual is unknown. As discussed in Falk and Knell (2004), it may also be the case that the reference group composition is endogenously specified by each individual and also changes over time. Empirical studies have mainly applied two strategies to solve this problem. One approach is to assume ad hoc criteria to define a reference group. An example of this would be to define a reference group as "all other individuals who are living in the same region, having similar age or education" (e.g., Clark and Oswald, 1996; McBride 2001, Ferrer-i-Carbonell, 2005; Luttmer, 2005). A second strategy is to ask people directly who they compare their income with. This strategy is more precise, yet recent results seem to indicate no difference in terms of estimated degree of positionality compared to previous findings based on ad hoc reference groups (Clark 
and Senik, 2010; Knight and Kingdon, 2010).

The GSOEP dataset does not include explicit reference group information and we therefore have to define reference groups using some rules. Our benchmark definition of a reference group is as used by Ferrer-i-Carbonell (2005), who uses the same dataset but with a shorter duration of panels when analyzing positional concerns in Germany. We consider the results of her study as a benchmark and compare our results with hers throughout our paper. The reference group defined in Ferrer-i-Carbonell (2005) is that an individual compares his or her absolute level of (post government transfer household) income with "all other people who are living in the same region (West or East Germany); who are in the same age group (younger than 25, 25-34, 35-44, 45-65, and 66 or older), and have acquired the same number of years of education (less than 10,10, 11, 12, and 12 or more years of education)." This reference group definition generates 50 different reference groups (Ferrer-i-Carbonell, 2005). We extend this reference group definition by introducing different orbits of comparisons and criteria of selection into reference groups. We use all of the 16 federal states of Germany, age, educational levels, gender, marital and employment status, number of children, health and all possible combinations. Using different criteria generates a high or low number of reference groups in each case. The number of individuals in the reference groups determines the precision of reference income estimates. Although it is possible to refine reference groups with other socio-economic and demographic characteristics, this would lead to imprecise estimates of reference income due to the small groups of people who would be able to satisfy such complicated criteria. We will present a detailed sensitivity analysis by experimenting with various alternative reference group definitions as in the bulk of the literature.

\section{$2.3 \quad$ Estimation Results}

Standard socio-demographic variables in SWB regressions: We first estimate various SWB functions with different specifications (OLS, ordered probit model, linear fixed and random effects models) while experimenting with the potential reference groups. We find similar signs, magnitudes, and significance of the 
parameters for common socio-economic and demographic characteristics as in the literature. We were able to replicate the results presented in Ferrer-i-Carbonell (2005) particularly well. Health, education, income, housing and marriage are some of the most commonly considered factors found to have positive relationships with SWB. Our results confirm most of the findings in the literature. We also find a very strong U-shaped relationship between age and SWB as is usually observed in these type of studies (e.g., Blanchflower and Oswald, 2008; Clark, 2007), with a minimum around age 40-45 depending on the exact specification (controlling for, e.g., the individual heterogeneity). ${ }^{6}$

Overall income comparisons: Table 1 reports the benchmark results of positional concerns in the first column. Since we are mainly interested in the relative income effects we only present the estimated marginal effects of this measure on SWB.

\section{Table 1 about here}

We start with the benchmark reference group definition used in Ferrer-i-Carbonell (2005). She uses "all other people living in the same region (West or East Germany), with the same age group (5 age categories) and with the same education level (5 education categories)." Previous studies in the literature suggest that there are no big differences between specifications in the estimation of the ordered data with linear models or ordered probit specifications (Ferrer-i-Carbonell and Frijters, 2004). However, we try several alternative specifications to test the sensitivity of the results. The first specification is OLS and the model indicates a statistically significant negative relationship between a reference group's mean income level and an individual's SWB. The size of the overall relative income effect is around -0.20 , on average. We then estimate a linear fixed effects models and a pooled ordered probit model to control for the ordinal nature of SWB measure and the unobserved individual effects (unobserved individual characteristics such as personality characteristics), which is potentially correlated with observed characteristics of individuals. Finally, we also

$6 \quad$ We do not report the full estimation results here, yet they can be provided by the authors upon request. 
present results from a random effect model since its estimates are more efficient than the fixed effect estimates, but may be inconsistent in the case of correlation. The estimated relative income parameter for the entire sample is robust with respect to the model specifications, and the results presented here are very much in line with the results reported in Ferrer-i-Carbonell (2005).

We further test the sensitivity of the results with respect to the reference group definitions using two additional reference group definitions in our initial analysis. We first extend the Ferrer-i-Carbonell (2005) reference group definition by considering the 16 federal states of Germany together with the previously used groups, namely same age (5 age categories as before) and same educational level (5 educational categories as before). In the second reference group definition, we also include gender. By and large, the results differ only slightly depending on specification of reference group and econometric specifications, as shown in Table 1, and the results are similar to those reported in Ferrer-i-Carbonell (2005).

Relative concerns over the life cycle: We now estimate the model given in (2) to be able to identify the life cycle pattern of the relative income effect on SWB. In the remaining columns of Table 1, we present results for the relationship between age and the relative income effect on SWB using the age intervals [20,30), $[30,40),[40,50),[50,60),[60,70)$, and $[70,80)$. The model involves interactions between absolute and relative income levels of individuals and the dummies of age categories conditional on the relative income, absolute income, time effect, birth cohort effects, many other socio-demographic variables, and also unobserved individual heterogeneity. ${ }^{7}$ We present results for four specifications, as above, and for three reference group definitions.

The relationship between age and the relative income effect on SWB is clearly not homogenous through the life cycle. The results do not vary much with the reference group definition. There is a consistent and robust relative income effect pattern across age: among young people (around 40 and younger) the effect on

$7 \quad$ The age brackets presented in the tables are completely arbitrary. We chose the intervals only for presentation purposes. The results are very robust to any classification; and the results obtained with narrower age categories can be obtained from the authors upon request. 
relative income on SWB seems to be either positive or insignificant. This result should be interpreted carefully; we suggest a signal effect interpretation that is based on Hirschman and Rothschild's (1973) "tunnel effect." Young people may consider a higher income in the reference group as a signal for a higher own income in the future which correlates with a higher current SWB. Relative income affects SWB negatively later in life, i.e., a status effect that gradually and slowly increases with age. Thus, the negative effect of relative income as found in the estimation for the overall population is driven by the negative relative income effect generated by people older than 40 . In short, the effect of relative income on utility is not homogeneous across the life cycle.

We will now in greater detail focus on the relationships between the relative income effect and age using Figure 1. Our dataset is large and thus allows for a high degree of flexibility to classify age categories into smaller brackets. We calculate results for 3-year age brackets, from age 20 to age 80 . The reference group is based on states (16 states), age (5 groups), and level of education (5 groups). The upper graph presents the result obtained from ordered probit and the lower is obtained from the linear fixed effects specification. Figure 1 clearly shows that the life cycle pattern of positional concerns resembles a step function. In the first step, the relative income effect is positive or slightly negative among people aged 20-35, and it gradually becomes negative and stabilizes as significantly negative around age 30-35. Note that the relative income effect is stable for a long time (with ordered probit specification) around the overall average relative income effect of -0.138 . The effect gradually becomes more and more negative after the early $60 \mathrm{~s}^{8}$ The pattern is almost the same in the case of the linear fixed effect specification. We present the results from this model in the lower part of Figure 1. The major difference between the two specifications is that the relative income effect is not as flat and stable in the case of the ordered probit model in middle age (35-60). It decreases slowly until the early

\footnotetext{
$8 \quad$ The results are almost the same with the other reference group definitions following the results presented in Table 1. We also split the age groups into smaller brackets of two years and even for one year. The precision of the results is decreased but the pattern remains. All results are available from the authors upon request.
} 
60 s and then continues to decrease but at an increasing rate thereafter.

Figure 1 about here

\subsection{Robustness Checks}

Table 1 presents the results for three definitions of reference groups. As can be seen, the results are highly stable. The basic finding is that individuals do have heterogeneous positional concerns across age: income comparisons generate a positive or slightly negative impact on the well-being of young people, yet this effect becomes increasingly negative with age. Below, we present the results for many other ad hoc reference groups using various alternative definitions to check the robustness of our findings.

Alternative reference groups with age windows: To investigate the robustness of our results, we examine the effect of different age windows, and special attention is given to the age groups used in the reference group definitions since our model specifications are also based on interactions between age and relative income. We use a long panel dataset, and this allows us to use age categories in the reference group in various ways. Since the actual size of the age window for an individual is unknown, we define it as the age of the individual $\mp k$ years, and to check the robustness of the results we set $k=3,4$, and 5 (see also discussion in McBride, 2001). Thus, the reference groups that we use are the states of Germany (16 states), own age $\mp k(k=3,4,5)$, and education (5 groups). The results are reported in Table 2. The overall relative income effect is negative as previously found, and the size is comparable to the findings of other studies in the literature using the same dataset (Ferrer-i-Carbonell, 2005). It is clear that the pattern of the relative income effect over the life cycle is very similar to the previously presented results. By and large, the results are robust to the age categorization and windows chosen in the reference groups.

Table 2 about here 
Alternative reference groups with other individual characteristics: A trivial observation is that individuals experience a chain of life-changing events throughout their life cycle. For example, a period of education ends the person joins the labor force, somebody who is single gets married, and then the number of children keeps changing over time. These life changes may lead the reference group composition of an individual to change as well. We can capture the dynamic shifts in reference groups using some more ad hoc criteria that account for major life events resulting from the changing individuals' own characteristics or changes in the individual's social context. Take for example single young people. It is reasonable to assume that these people compare their income with other young singles. However, these individuals may get married one day and consequently form a new reference group comparing married people. The panel aspect of the dataset used here allows us to incorporate such life events into reference groups in a dynamic way. Yet, as mentioned above, there is a trade-off between the precision of selecting a reference group and the sample size when calculating the relative income in the reference group. Therefore, we have been parsimonious on the number of criteria even though the panel aspect of the data is long and the sample size is large.

The results are shown in Table 3, where we also present the second set of robustness checks for the effect of reference group definitions. We also test many other possibilities, but only present some of them due to space limitations. The base criteria in each case are "states (16 states), age (5 groups) and education (5 groups)." We add marital status (married, single, and divorced or widowed), number of children (0, 1 , and 2 or more), employment status (employed or unemployed), and subjective health status (very poor health, poor health, neither poor nor good health, good health, and very good health). It is clear that due to the mentioned trade-off, the estimators have lost their precision. However, the life-cycle pattern found above is the same as before in most cases.

Table 3 about here 
Gender differences: We sort individuals by gender, and conduct a similar analysis to investigate life-cycle differences by gender. We estimate the same models as in the previous sections, but this time the data are split by gender. We use the reference group that is based on states (16 states), age (5 age groups), and level of education (5 groups). Naturally, splitting the dataset by gender implies that gender is also included in the reference group definition. We convey the results in Table 4. There is no big difference between males and females, especially in the case of ordered probit specifications. Controlling for individual heterogeneity leads to a large positive and significant relative income parameter for the young females.

We present the results in Figure 2 and these results are very similar to those in Figure 1. We estimate the models for 3-year age categories and interactions with the relative income of individuals occurring in the particular age group. Positional concerns of females show a pattern that is more similar to the overall results, as presented in Figure 1. Again, there are three clear stages: young people experience either positive or slightly negative relative income concerns. During middle age the effect is relatively stable and decreases slowly for many years. It then increases during the early 60s and becomes relatively stable a few years late, especially after 70. The second part of Figure 2 suggests that the positional concerns of males show a similar, yet smoother pattern. The relative income effect is positive until the early 30s and then gradually becomes more negative before it stabilizes later in life.

Table 4 about here

Figure 2 about here

\subsection{Absolute income effect through the life cycle}

Almost all empirical work in the SWB literature suggests that a person with a higher absolute income is more likely to report a higher level of SWB. This is an expected result considering that more income can lead to more consumption and more utility. An interesting question is whether the marginal utility of absolute income is the same across age. Thus, we examine whether the absolute income 
effect is also heterogeneous across age and present the life cycle pattern of absolute income on SWB.

Previous analyses already include absolute income levels and their interactions with age categories in the specifications (equation (2)). We simply present the marginal effect of absolute income in Table 5 split by age categories as above. As with relative income, the impact of absolute income on SWB through the life cycle is not homogenous: it (the marginal utility of income) is lower for young people (remember that we found a positive relative income effect above for this group) and gradually increases until people are in their 40s. The absolute income effect peaks around age 40 and then gradually decreases until the early 60s. The parameter becomes stable after this age, right around the overall average level of the absolute income effect. The results are also presented in Figure 3 by using 3-year age group intervals.

\section{Table 5 about here}

Figure 3 about here

\section{Evidence from a Survey Experiment}

In this section we analyze the life-cycle pattern of positional concerns using a survey experimental approach since we believe that there are factors that may bias the results presented above. First, using subjective measures of well-being may involve some bias since such measures may involve a high degree of noise due to underlying multidimensional circumstances determining life satisfaction or happiness. ${ }^{9}$ Second, the SWB approach suffers from the problem concerning reference group definition. In the previous section we defined various alternative reference groups and various robustness checks by experimenting with different ad hoc criteria of reference groups to tackle this problem. Third, the SWB approach does not allow testing the positional concern for alternative consumption goods such as cars and leisure time. Therefore, we analyze the positional concerns through the life cycle using an alter-

$\overline{9}$ See Clark (2008) for a summary of the arguments against this view. 
native approach based on a tailor-made survey experiment where we control some of the sources of bias. ${ }^{10}$ We both test the robustness of previous results and bring new evidence on the relationship between age and positional concerns. ${ }^{11}$ The experimental design and data used in this paper are taken Carlsson et al. (2007). ${ }^{12}$ Having split the experimental data by age categories, we estimate the marginal degree of positional concerns for these age groups as in the case of SWB approach.

\subsection{The experiment}

The experimental design that we use aims to investigate positional concerns for (i) income, (ii) working hours (or leisure), and (iii) the consumption value of a car. The underlying preference structure is assumed to follow the utility function in (3).

$$
U_{i}\left(y_{i}, y_{i}-\bar{y}_{s}^{r}\right)=(1-\lambda) y_{i}+\lambda\left(y_{i}-\bar{y}_{s}^{r}\right)
$$

where $U_{i}$ indicates the utility of an individual $i$; $y_{i}$ is the absolute level of income of the individual; $\bar{y}_{s}^{r}$ is the relative income of people in the society $s$; and $\lambda$ is the proportion of a change in utility that comes from an increase in relative income after an increase in own absolute income. ${ }^{13}$ Note that $\lambda$ is expected to be positive based on the utility function specified in equation (3), and that a higher $\lambda$ indicates a stronger positional concern. ${ }^{14}$

The study was conducted using a survey, and Figure 4 below shows the example question presented after the main instructions to illustrate the exercise to come. It as this was the first good addressed in the survey. In each choice situation, there were two societies, $A$ (a society where absolute income was maximized) and $R$ (a

10 The experimental approach has some disadvantages. Firstly, the survey experimental approach used in this paper is based on hypothetical scenarios that may not reflect the actual positionality preferences of subjects. Secondly, the sample size is small, as in the most experimental studies in the literature (see Carlsson, 2010) for the pros and cons of using the survey experimental approach to test positional concerns)

11 Note that the current paper is the first paper in the literature that uses the SWB and experimental methods to test the positional concerns of the individuals.

12 See Carlsson et al. (2007) for the details of the experiment.

13 An alternative is to use a ratio utility function, i.e., $U_{i}\left(y_{i}, y_{i} / \bar{y}_{s}^{r}\right)$, but the empirical results are similar (e.g., Alpizar et al., 2005).

14 Note that the positive sign of $\lambda$ does not imply a utility increase as in the case of the SWB approach. 
society where relative income was maximized), and the subjects were asked to choose one of them. The societies $(A$ and $R$ ) in the choice situations were identical except that the levels of the goods (income, value of a car, and working hours) changed for the imaginary relative for the future in order to facilitate calculation of marginal degree of positionality. It was also stressed that the general price level was the same and similar to the current levels of today.

\section{Figure 4 about here}

If a respondent is indifferent between living in these two societies, then we know that $y_{i, A}-\lambda \bar{y}_{A}^{r}=y_{i, R}-\lambda \bar{y}_{R}^{r}$. We can then calculate the degree of positional concern from the above example as:

$$
\lambda=\frac{y_{i, A}-y_{i, R}}{\bar{y}_{A}^{r}-\bar{y}_{R}^{r}}=\frac{20,000-18,000}{25,000-15,000}=0.20
$$

Thus, if a respondent is indifferent between the societies presented in Figure 4, then the marginal degree of positional concern, $\lambda$, is 0.20 . If the respondent chooses society $A$ (in which the relative income position of the imaginary future relative is better compared to society $R$ ), then $\lambda<0.20$, and vice versa. As the respondents were asked to make choices between two societies with different implicit marginal degree of positional concern, we can calculate the degree of positional concern within an upper and a lower bound of the degree of positionality.

\subsection{Results of the Experiment}

We begin by presenting some descriptive results from Carlsson et al. (2007) in Table 6, where we split the experimental data by good and age category similar to above. Subjects are classified into four age categories $[20,40),[40,50),[50,60)$, and $[60,80]$ since the sample size is much smaller compared to the SWB approach. The first part of Table 6 summarizes the full experimental design and presents the implicit marginal degree of positionality when alternative $R(1-3)$ is chosen instead 
of alternative $A$.

\section{Table 6 about here}

In the second part, we present the proportion of individuals who choose society $R$ in different choice situations by age categories, i.e., the proportion of subjects with a degree of positional concern that at least corresponds to indifference in the specific choice situation. We consider first the proportion of all subjects who choose society $R$ in the income experiment. $76.1 \%$ of the subjects choose the positional alternative, society $R$, when the implicit marginal degree of positionality implied in the choice is 0.25 (this also implies that $23.9 \%$ of the subjects choose society $A$ in which the absolute income is higher). The proportions of the subjects who choose society $R$ gradually decreases in the subsequent choice situations as the implicit marginal degree of positionality increases from 0.25 to 0.50 and then to 0.74 resulting $52.8 \%$ and $47.7 \%$ choose society $R$ in these choice situations. The interpretation is the same for the other choice situations presented in Table 6. Overall, a large number of subjects choose society $R$ in the first choice situation for each good, reflecting some degrees of positional concern. As expected, there is a substantially higher degree of positionality for income and a luxury car, compared to working hours (leisure time).

The results split by age groups show a similar pattern compared to the results obtained with SWB data. In a preliminary comparison across age groups, the key finding is that older people are more likely to choose society $R$ compared to young people with respect to both income and car consumption. We observe that $60.6 \%$ of people who are younger than 40 choose society $R$ (with a 0.25 implicit marginal degree of positionality) in the income experiment. The proportion of the subjects who chose society $\mathrm{R}$ increase with age. The corresponding proportion is $83.3 \%$ in the income experiment for people older than 60 . The pattern is similar for other marginal degrees of positionality for income as well as for the market values of a car. However, the pattern is reversed for of leisure time, suggesting that there may be different life-cycle patterns across consumption goods.

To make our results directly comparable to previously presented studies (e.g., Alpizar et al., 2005; Carlsson et al., 2007), we also estimate the mean marginal degree of positionality $(M M D P)$ by age group using a non-parametric estimator. We use 
the Spearman-Karber estimator to obtain the mean values, and this estimator is robust to small sample size (e.g., Carlsson et al., 2007). The formulation of the Spearman-Karber estimator is given as: ${ }^{15}$

$$
M M D P_{S K}=\sum_{k=1}^{4} \frac{\left(t_{k}+t_{k+1}\right)\left(P_{k}-P_{k+1}\right)}{2},
$$

where $t_{k}$ is the implicit marginal degree of positionality for the choice situation $k=1,2,3,4$; and $P_{k}$ is the actual proportion of the subjects who picked society $R$ in the $k$ th choice situation. ${ }^{16}$ The estimated mean degree of positionality with the Spearman-Karber estimator is presented in Table 6 together with the $95 \%$ confidence intervals. As expected from the descriptive statistics, we find a higher degree of positional concern for income and car consumption compared to the case of leisure. Moreover, there are differences across age groups. The estimated marginal degree of positional concern increases with age for the case of income and car consumption, while the opposite is found for leisure.

\section{Table 7 about here}

The results presented in the upper part of Table 7 are very much in line with the results obtained using the SWB approach with the German dataset (GSOEP). To be able to make a direct comparison to the results of SWB approach, we estimate the previous models (1)-(3) with the same age classification as in the survey experimental approach (4 age categories: $[20,40),[40,50),[50,60)$, and $[60,80])$. The results obtained using the GSOEP dataset are presented below the experimental results in Table 7 . They are highly similar: the positional concerns are lower for the young

15 An alternative is the Kaplan-Mayer-Turnbull estimator, which by construction results in a lower mean degree of positionality.

16 In order to calculate the $95 \%$ confidence intervals, we need to calculate the standard errors. The variance of the Spearman-Karber estimator is calculated as

$$
\operatorname{Var}\left[M M D P_{S K}\right]=\sum_{k=2}^{4} \frac{\left(t_{k+1}+t_{k-1}\right)^{2} P_{k}\left(1-P_{k}\right)}{4\left(N_{k}-1\right)}
$$

where $N_{k}$ is the number of the respondent in the $k$ th choice situation. Note that the first and last choice situations are assumed to have 0 and 1 as the implicit degree of positionality. 
and increase as people get older.

We use one more microeconomic panel dataset to further check for the robustness of the results, namely one of the other widely used datasets in the literature: the British Household Panel Survey (BHPS). This dataset is a panel covering 16 periods, which allows us to obtain comparable results with the results obtained from GSOEP. We examine the life-cycle patterns of positional concerns with the same specifications as before, and exactly the same variables as those used in the case of GSOEP. We use the same age categories, i.e., $[20,40),[40,50),[50,60)$, and $[60,80]$, and the same reference group definition, i.e., states (19 states of Great Britain), age (5 age groups), and level of education (5 groups) in order to obtain comparable results. The observed well-being is based on the mental health measure GHQ-12 (e.g., Clark and Oswald, 1996). We find very similar results with increasing positional concerns by age with some differences between the German and the British data. The result based on BHPS and GHQ-12 suggest that the life cycle pattern of positional concern is similar to a inverted U-shape: it is lower for the young people and increases during the middle age (as previously found with the GSOEP) but it is again lower as people get older.

\section{Discussions and Conclusions}

Using subjective well-being and survey experimental approaches, we undertake a comprehensive investigation of life cycle patterns of positional concerns, something that has not been done before in the literature. In the subjective well-being approach we use two of the longest panel datasets (GSOEP, and also BHPS in some cases) available and a survey experiment which is conducted among Swedish adults. Regardless of approach and dataset used, the results are robust and show that people do have positional concerns. We find that people's positional concerns are not homogenous along the life span. Both approaches that we use in the paper generate the same result: the degree at which people are concerned about their relative level of income or consumption increases with age. When people are young, they are less positional or even experience a welfare premium comparing their income 
or consumption to comparable others. However, the positional concerns gradually increase as they get older. This result supports the claim that the different phases in one's life lead to age-related heterogeneity in positional concerns. This pattern holds when variables are added that capture birth cohort effects, time effects and individual unobserved characteristics. The survey experiment suggests that different consumption goods generate different patterns of positionality over the life span. The positional concerns of people toward different goods not only differ at any given point in time but also change over time. For instance, we report that as people get older they exhibit higher and higher positional concerns when it comes to income and car consumption, but the result is reversed when the good is working hours (leisure).

This paper is the first attempt to analyze the life-cycle patterns of positionality using both subjective well-being data and experimental methods. Our results are highly stable and show that the impact of positional concerns increases smoothly with age. Future research should attempt to link these findings in order to explain the Easterlin paradox more directly and quantitatively. Also,we find differences in the life-cycle patterns of positional concerns across goods as in the case of preferences for working hours. The experimental design in this study only helps to identify the differences across goods but not the reasons behind them. Future research should also focus on cross-country and cultural differences in the positional concerns across age, as the phases experienced throughout the life cycle may differ across cultures and countries.

\section{References}

[1] Abel, A.B. (1990). Asset prices under habit formation and catching up with the Joneses, American Economic Review, 80: 38-42.

[2] Abel, A.B. (2005). Optimal taxation when consumers have endogenous benchmark levels of consumption, Review of Economic Studies, 72: 21-42. 
[3] Akay, A., Martinsson, P., and Medhin., H. (2011). Does Positional Concern Matter in Poor Societies? Evidence from a Survey Experiment in Rural Ethiopia. World Development, 40: 428-435.

[4] Akay, A., Bargain, O. and K.F. Zimmermann (2011). Relative Concerns of Rural-to-Urban Migrants in China, Journal of Economic Behavior and Organization, forthcoming.

[5] Akay, A. and Martinsson, P. (2011). Does Relative Income Matter for the Very Poor? Evidence from Rural Ethiopia, Economics Letters, 110: 213-215.

[6] Alpizar, F., Carlsson, F. and Johansson-Stenman, O. (2005). How much do we care about absolute versus relative income and consumption?, Journal of Economic Behavior and Organization, 56: 405-421.

[7] Aronsson, T., and Johansson-Stenman, O. (2008). When the Joneses' Consumption Hurts: Optimal Public Good Provision and Nonlinear Income Taxation, Journal of Public Economics, 92: 986-997.

[8] Blanchflower, D.G., and Oswald, A.J. (2008). Is Well-Being U-Shaped over the Life Cycle?, Social Science \& Medicine, 66: 1733-1749

[9] Bookwalter, J., and Dalenberg, D.R. (2009). Relative to What or Whom? The importance of Norms and Relative Standing, World Development, 38: 345-355.

[10] Boskin, M. and Sheshinski, E. (1978). Optimal redistributive taxation when individual welfare depends upon relative income, Quarterly Journal of Economics, 92: 589-601.

[11] Brickman, P.C.D. and Campbell, D. (1971). Hedonic relativism and planning the good society. In M. H. Appley (ed.), Adaptation-Level Theory: A Symposium. New York. Academic Press.

[12] Carlsson, F., O. Johansson-Stenman, and P. Martinsson, (2007). Do You Enjoy Having More than Others? Survey Evidence of Positional Goods, Economica, 74: $586-598$. 
[13] Carlsson, F. (2010). Design of Stated Preference Surveys: Is There More to Learn from Behavioral Economics?, Environmental and Resource Economics, 46: $167-177$.

[14] Carroll, C., Overland, J. and Weil, D.N. (1997). Comparison utility in a growth model, Journal of Economic Growth, 2: 339-67.

[15] Clark, A.E. and Oswald, A.J. (1996). Satisfaction and comparison income, Journal of Public Economics, 61: 359-81.

[16] Clark, A.E., P. Frijters, and M.A. Shields. (2008). Relative Income, Happiness, and Utility: An Explanation for the Easterlin Paradox and Other Puzzles, Journal of Economic Literature, 46: 95-144.

[17] Clark, A.E., Oswald, A.J., Warr, P. (1996). Is Job Satisfaction U-Shaped in Age?, Journal of Occupational and Organizational Psychology, 69: 57-81.

[18] Clark, A.E., (2007). Born To Be Mild? Cohort Effects Don't (Fully) Explain Why Well-Being Is U-Shaped in Age, IZA DP, Nr: 3170.

[19] Clark, A.E., and C. Senik, (2010) Who Compares to Whom? The Anatomy of Income Comparisons in Europe, Economic Journal, 120: 573-594.

[20] Caporale, G.M., Y. Georgellis, N. Tsitsianis, and Y.P. Yin, (2009). Income and happiness across Europe: Do reference values matter?, Journal of Economic Psychology, 30: 42-51.

[21] Di Tella, R., MacCulloch, R. and Haisken-DeNew, J.P. (2011). Happiness adaptation to income and to status in an individual panel, Journal of Economic Behavior and Organization, 76: 834-852

[22] Dolan, P., T. Peasgood and M. White (2008). Do We Really Know What Makes Us Happy?A Review of the Economic Literature on the Factors Associated with SWB, Journal of Economic Psychology, 29: 94-122.

[23] Duesenberry, J. (1949). Income, Saving, and the Theory of Consumer Behavior. Cambridge, MA: Harvard University Press. 
[24] Easterlin, R. (1974). Does economic growth improve the human lot? Some empirical evidence. In David, R. and Reder, R. (Eds.), Nations and Households in Economic Growth: Essays in Honor of Moses Abramovitz. New York: Academic Press.

[25] Easterlin, R.A. (1995). Will raising the incomes of all increase the happiness of all?, Journal of Economic Behavior and Organization, 27: 35-47.

[26] Falk, A. and Knell, M. (2004). Choosing the Joneses: Endogenous goals and reference standards, Scandinavian Journal of Economics, 106: 417-435.

[27] Ferrer-i-Carbonell, A. (2005). Income and well-being: An empirical analysis of the comparison income effect, Journal of Public Economics, 89: 997-1019.

[28] Ferrer-i-Carbonell, A. and Frijters, P. (2004). How important is methodology for the estimates of the determinants of happiness?, Economic Journal, 114: 641-659.

[29] FitzRoy, F. R., Nolan, M., and Steinhardt, M. F. (2011). Age, Life-Satisfaction, and Relative Income: Insights from the UK and Germany, IZA Discussion Papers, No: 6045.

[30] Frank, Robert H. (1985). The Demand for Unobservable and Other Nonpositional Goods, American Economic Review, 75: 101-16.

[31] Frey, B.S., and A. Stutzer. (2002). What Can Economists Learn from Happiness?, Journal of Economic Literature, 40: 402-435.

[32] Frijters, P., Shields, M.A. and Haisken-DeNew, J.P. (2004). Money does matter! Evidence from increasing real incomes in East Germany following reunification, American Economic Review, 94: 730-741.

[33] Hirschman, A. with M. Rothschild (1973): The changing tolerance for income inequality in the course of economic development, Quarterly Journal of Economics, 87: 544-565. 
[34] Johannsson-Stenman, O., Carlsson, F., and Daruvala, D. (2002). Measuring future grandparents' preferences for equality and relative standing, Economic Journal, 112: 362-383.

[35] Kahneman, D., and R. Sugden, (2005). Experienced Utility as a Standard of Policy Evaluation, Environmental and Resource Economics, 32: 161-181.

[36] Kingdon, G. and J. Knight (2007). Community, Comparisons and Subjective Well-Being in a Divided Society, Journal of Economic Behavior and Organization, 64: 69-90.

[37] Kingdon, G., L. Song, L. and J. Knight, (2009). SWB and its determinants in rural China, China Economic Review, 20: 635-649.

[38] Knight, J. and R. Gunatilaka (2010). Great Expectations? The SWB of RuralUrban Migrants in China, World Development, 38: 113-124.

[39] Levinson, D. (1977). The Mid-Life Transition, Psychiatry, 40: 99-112.

[40] Levinson, D., Darrow, C. N., Klein, E. B., Levinson, M. H., \& McKee, B. (1978). The seasons of a man's life. New York: Knopf. J., with Darrow, C. N., Klein, E. B., Levinson, M. H. \&

[41] Ljungqvist, L. and Uhlig, H. (2000). Tax policy and aggregate demand management under catching up with the Joneses, American Economic Review, 90: 356-66.

[42] Luttmer, E. (2005). Neighbors as negatives: Relative earnings and well-being, Quarterly Journal of Economics, 120: 963-1002.

[43] McBride, M. (2001). Relative-income effects on SWB in the cross-section, Journal of Economic Behavior and Organization, 45: 251-278.

[44] Neumark, D. and Postlewaite, A. (1998). Relative income concerns and the rise in married women's employment, Journal of Public Economics, 70: 157-183.

[45] Oswald, A.J. (1997). Happiness and economic performance, Economic Journal, 107: $1815-1831$. 
[46] Park, Y. (2006). The second paycheck to keep up with the Joneses: Relative income concerns and labor market decisions of married women. Connecticut College, mimeo.

[47] Ravallion, M., and Lokshin, M., (2000). Who Wants to Redistribute? The Tunnel-Effect in 1990s Russia, Journal of Public Economics, 76: 87-104.

[48] Ravallion, M. and Lokshin, M., (2002). Self-rated economic welfare in Russia, European-Economic Review, 46: 1453-1473.

[49] Runciman, W. G. (1966). Relative Deprivation and Social Justice. University of California Press, Berkeley.

[50] Senik, C. (2004). When Information Dominates Comparison: A Panel Data Analysis Using Russian Subjective Data, Journal of Public Economics, 88: 2099-2123.

[51] Senik, C., (2005) Income distribution and well-being: what can we learn from subjective data?, Journal of Economic Surveys, 19: 43-63.

[52] Senik, C. (2008). Ambition and Jealousy. Income Interactions in the "Old Europe" versus the "New Europe" and the United States, Economica, 75: 495-513

[53] Senik, C., (2009). Direct Evidence on Income Comparisons and Their Welfare Effects, Journal of Economic Behavior and Organization, 72: 408-424.

[54] Solnick, S.J. and Hemenway, D. (1998). Is more always better?: A survey on positional concerns, Journal of Economic Behavior and Organization, 37: 373383.

[55] Solnick, S., and D. Hemenway, (2007) Positional Goods in the United States and China, Journal of Socio-Economics, 36: 537-545.

[56] Stevenson, B., and Wolfers, J., (2008). Economic Growth and SWB: Reassessing the Easterlin Paradox. Working Paper.

[57] Stutzer, A. (2004). The role of income aspirations in individual happiness, Journal of Economic Behavior and Organization, 54: 89-109. 
[58] van Praag, B. M. S. and A. Ferrer-i-Carbonell (2008). Happiness Quantified: A Satisfaction Calculus Approach. Oxford University Press.

[59] van Praag, B.M.S., Frijters P. and Ferrer-i-Carbonell, A. (2003). The Anatomy of SWB, Journal of Economic Behavior and Organization, 51: 29-49.

[60] Winkelmann, L., and Winkelmann, R. (1998). Why are the unemployed so unhappy? Evidence from panel data, Economica, 65: 1-15

[61] Woittiez, I. and Kapteyn, A. (1998). Social interactions and habit formation in a model of female labour supply, Journal of Public Economics, 70: 185-205.

\section{Appendix: The experiment}

In this part of the questionnaire we require you to choose which society you consider to be the best one for an imaginary person living two generations into the future. You can, for example, imagine a grandchild, great grandchild or another relative that you are choosing for. By 'best' we mean the society in which your future relative will be most content.

- The difference between the societies is the income level or the amount of consumption for a certain good of your future relative, and the average income and consumption of the society.

- The variety of goods and their prices are the same for both societies. For 100 SEK you can buy the same goods and the same amount in both societies. Prices are expressed in today's price level.

- It is important that you focus your answer on what is in the best interest of the imagined person, and nothing else. There is no "correct" response to these questions and we ask you to reflect on the choices carefully.

\section{Example}

In the example below your future relative earns 2000 SEK more in society A compared with society B. You can also see that your future relative earns $5000 \mathrm{k} /$ month less than the average income in society A and 3000 $\mathrm{SEK} /$ month more than the average in society B.

Society A

- Your relative's income is $20000 \mathrm{SEK} / \mathrm{month}$ after tax.

Society B

- The average income in society is $25000 \mathrm{SEK} /$ month after tax.

- Your relative's income is $18000 \mathrm{SEK} /$ month after tax.

- The average income in society is $15000 \mathrm{SEK} / \mathrm{month}$ after tax.

We require you to choose which society you consider to be the best one for your future relative; that is, the society in which your future relative will be most content. It is important that you focus your answer solely on this; that is: which society is the best for your future relative? You should not consider which society is best on the whole. 


\section{Question 1 Income for your future relative}

Choose between society A and B for your future relative.

Society A

Society B
- Your relative's income is $27000 \mathrm{SEK} /$ month after tax.

- The average income in society is $30000 \mathrm{SEK} /$ month after tax.

- Your relative's income is $25250 \mathrm{SEK} /$ month after tax.

- The average income in society is $22950 \mathrm{SEK} / \mathrm{month}$ after tax.

Everything else is the same in the two societies, including the price level. In both society A and B your relative works 40 hours per week, which is same as the average number of working hours. Choose the society that you consider to be the best for your future relative.

Society A

Society B

\section{Question 2 Working hours and leisure for your future relative}

Choose between society A and B for your future relative. The societies are the same except for the information given below.
Society A
- Your relative's working hours are 40 hours per week.
Society B
- Average working hours are 36 hours per week.
- Your relative's working hours are 42.5 hours per week.
- Average working hours are 46 hours per week.

Everything else is the same in the two societies, including the price level. In both society A and B your relative's monthly income is $20000 \mathrm{SEK}$, which is the same as the average income. Choose the society that you consider to be the best for your future relative.

Society A

Society B 


Question 3 Market value of the car for your future relative
Choose between society A and B for your future relative. The societies are the same except for the information
given below. This means the consumption of all other goods is the same in both societies even if the market value
of cars is higher in one society. The company at which your relative works provides a company car.
Society A
- Your relative's company car is a few years old with a market value of
90000 SEK.
- The average market value of cars in the society is 100000 SEK
84200 SEK
- The average market value of cars in the society is 76500 SEK
society that you consider the best for your future relative.
Society A
Society B




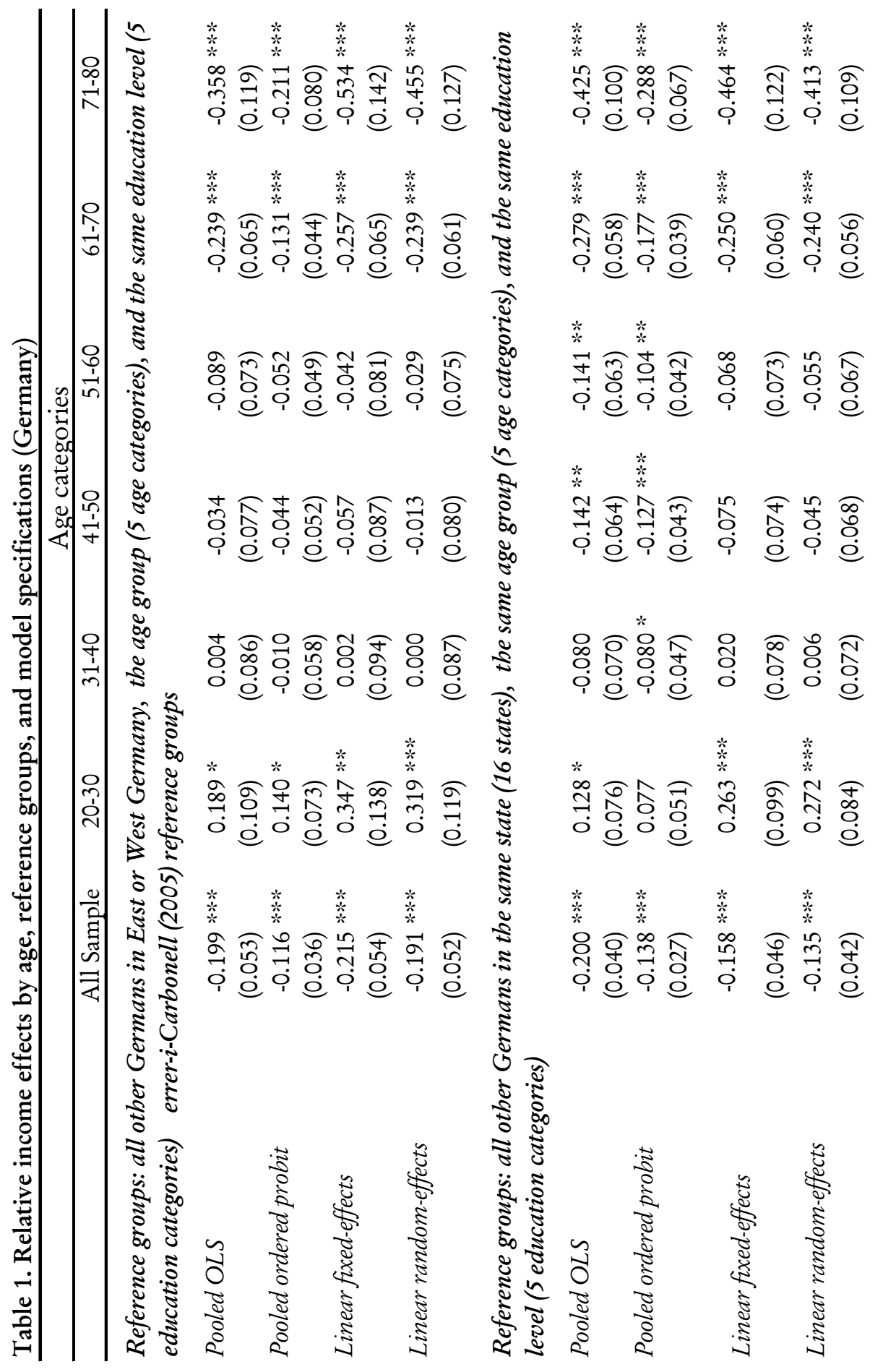




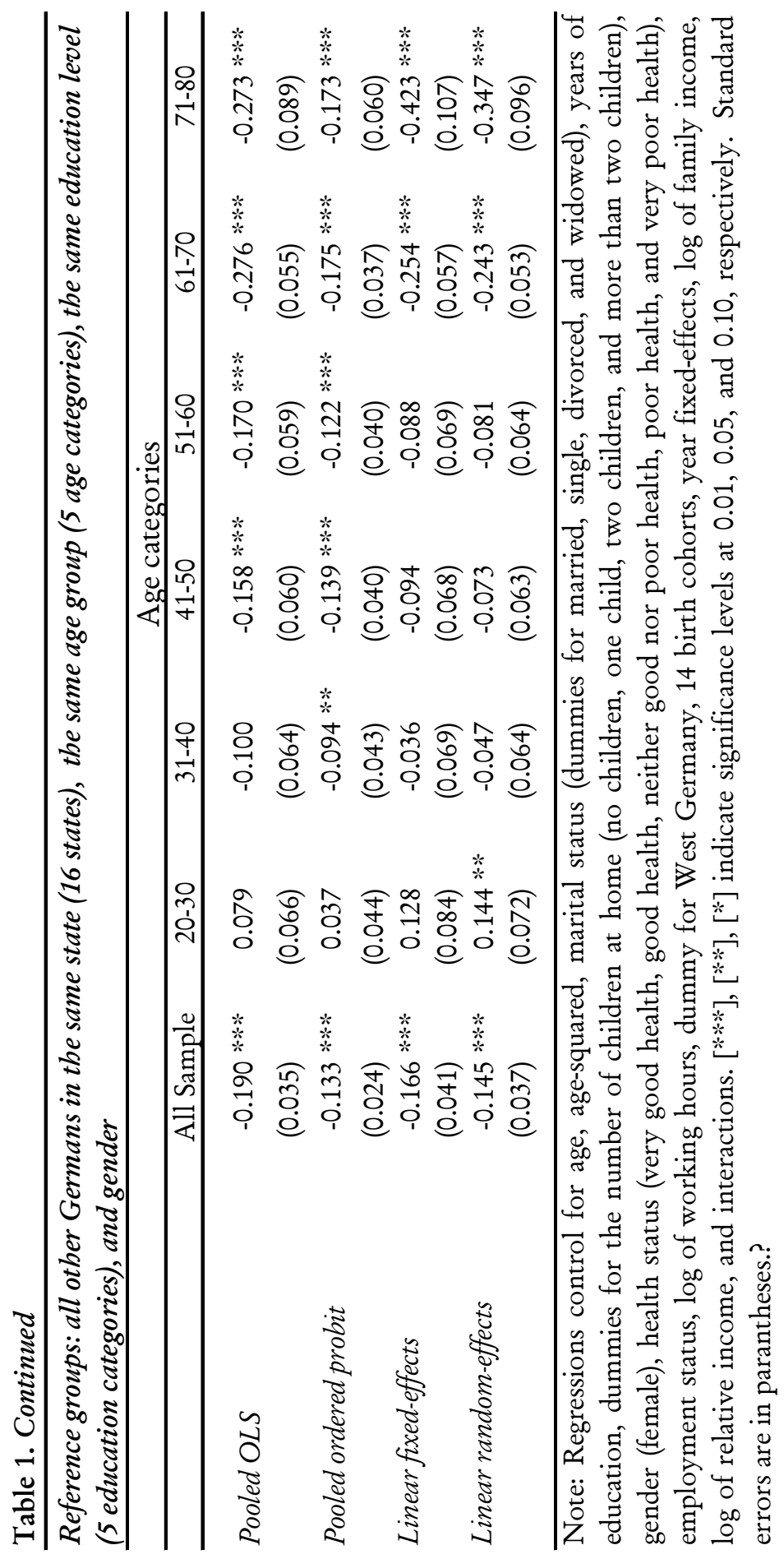




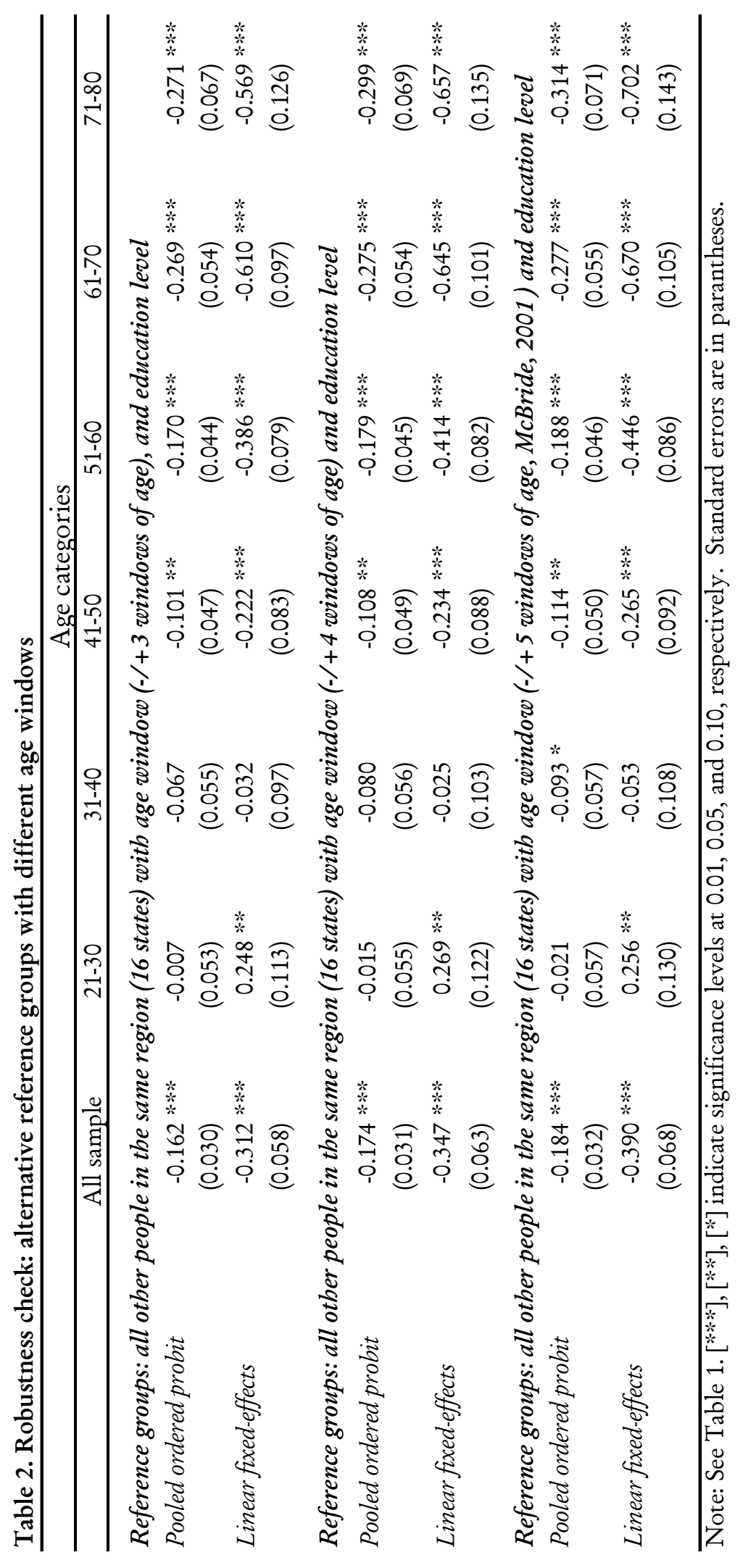




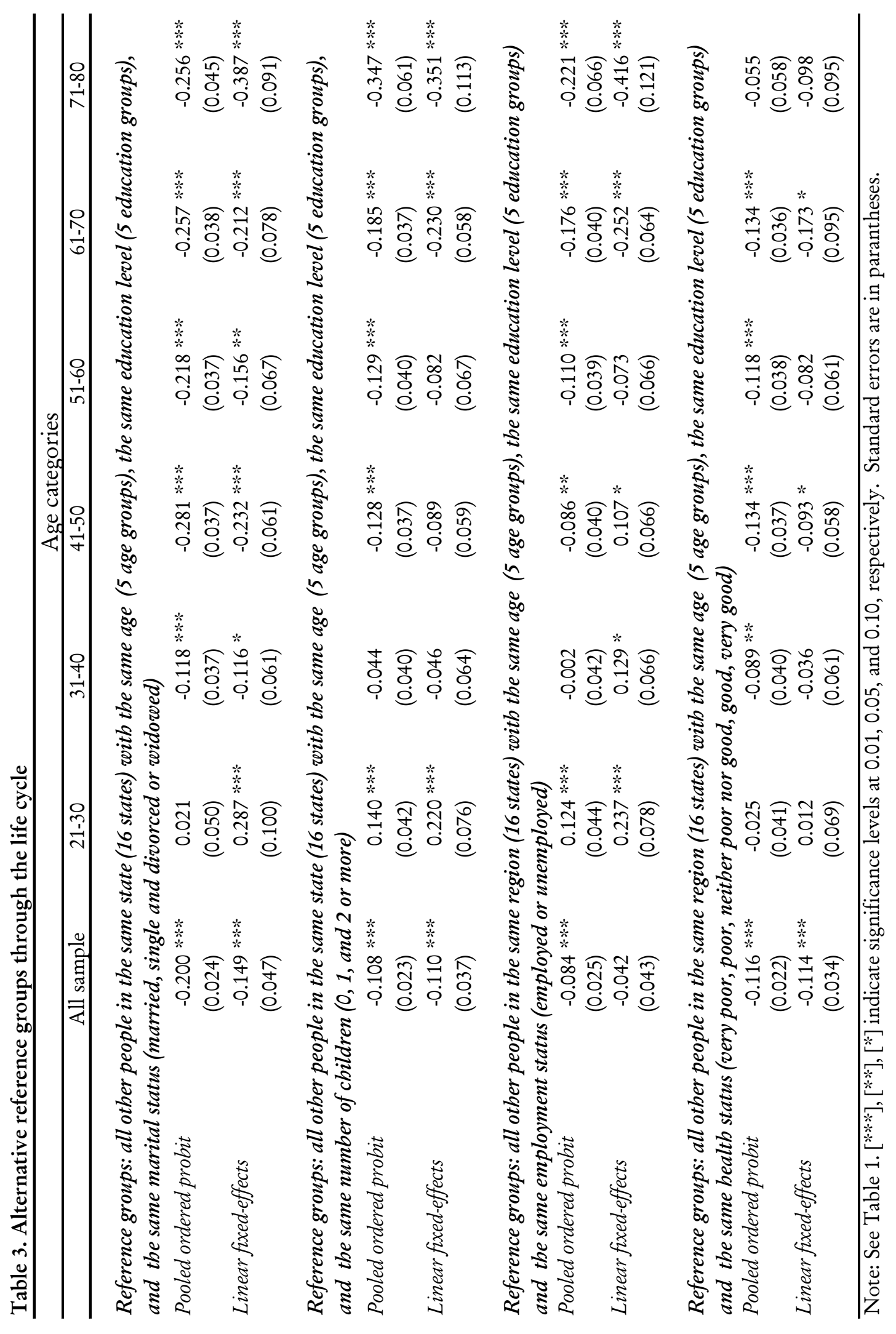




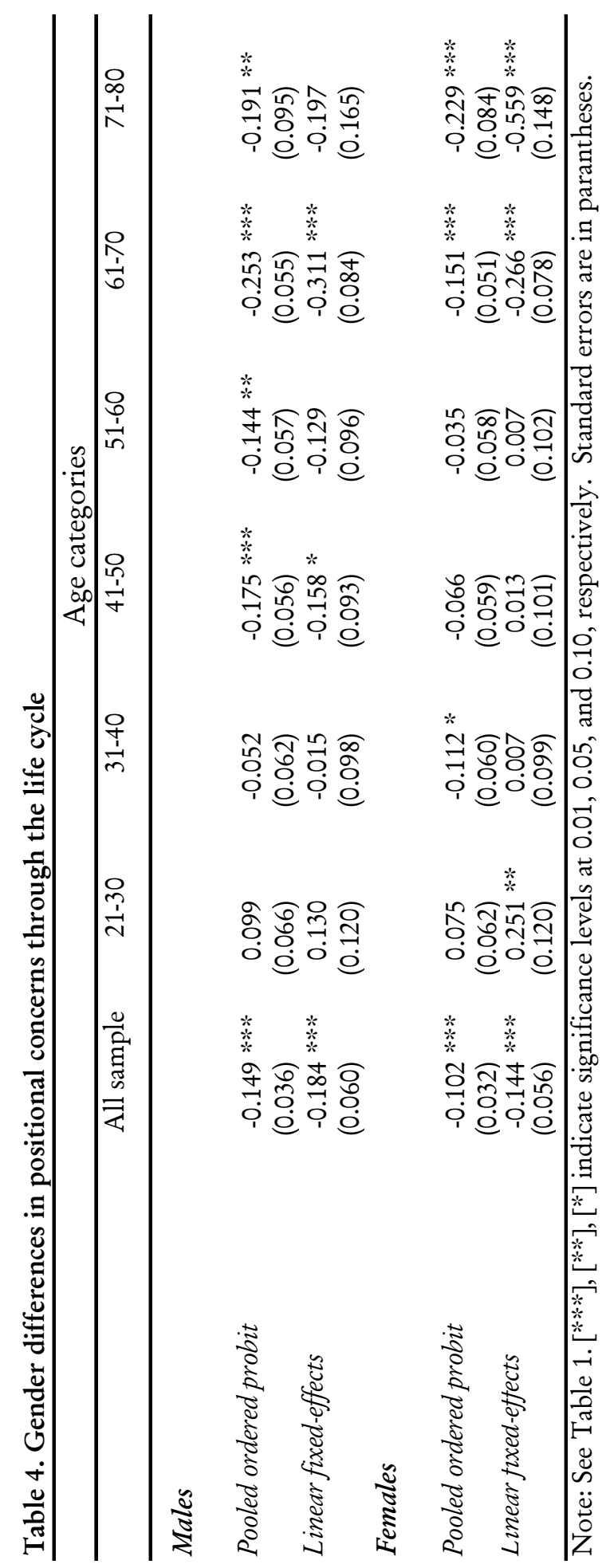




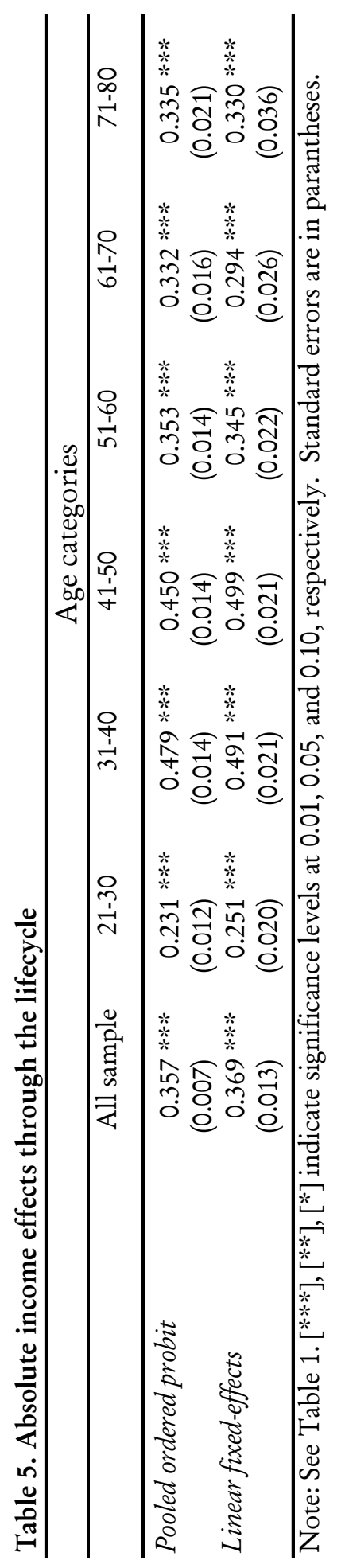




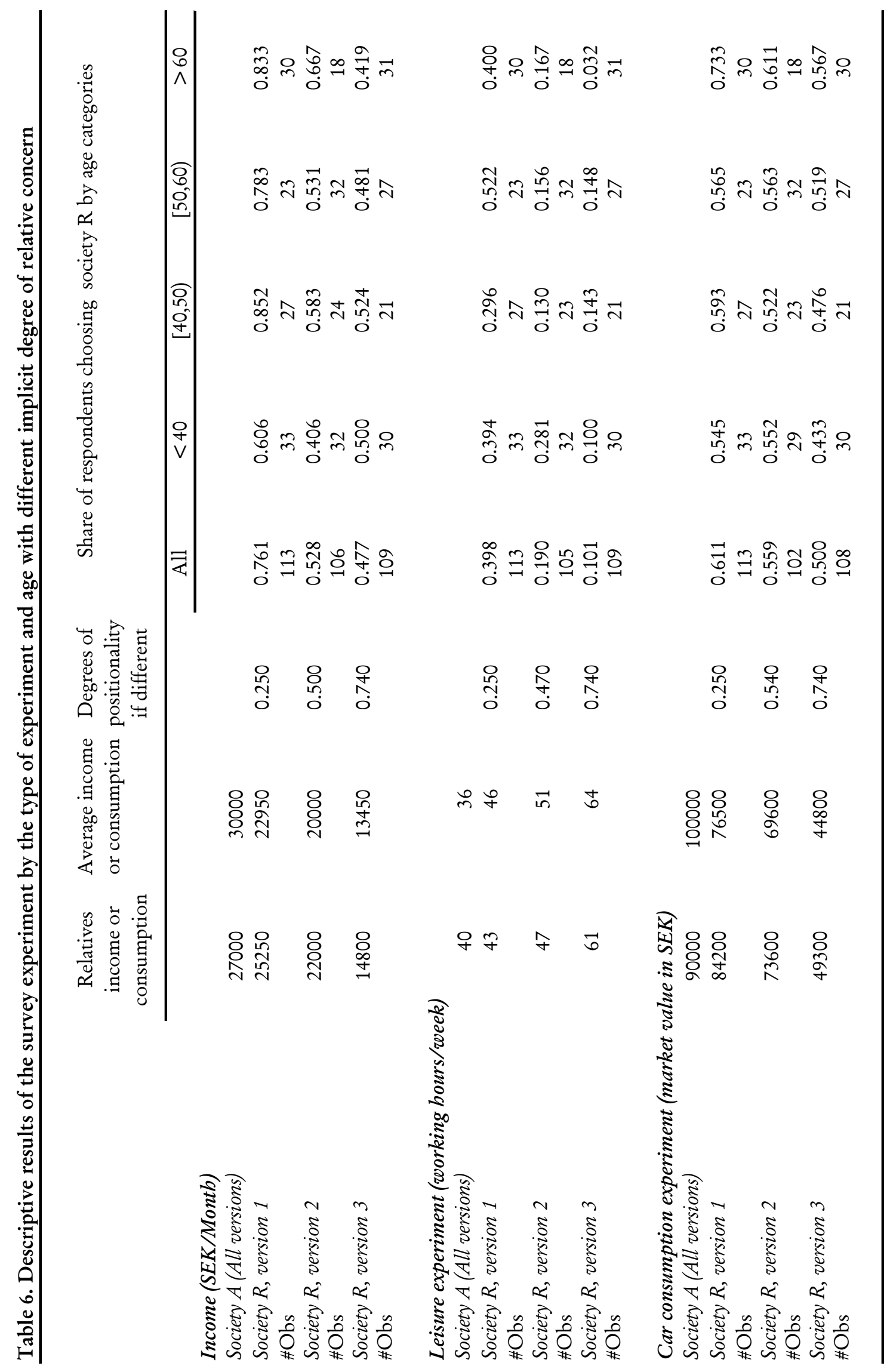




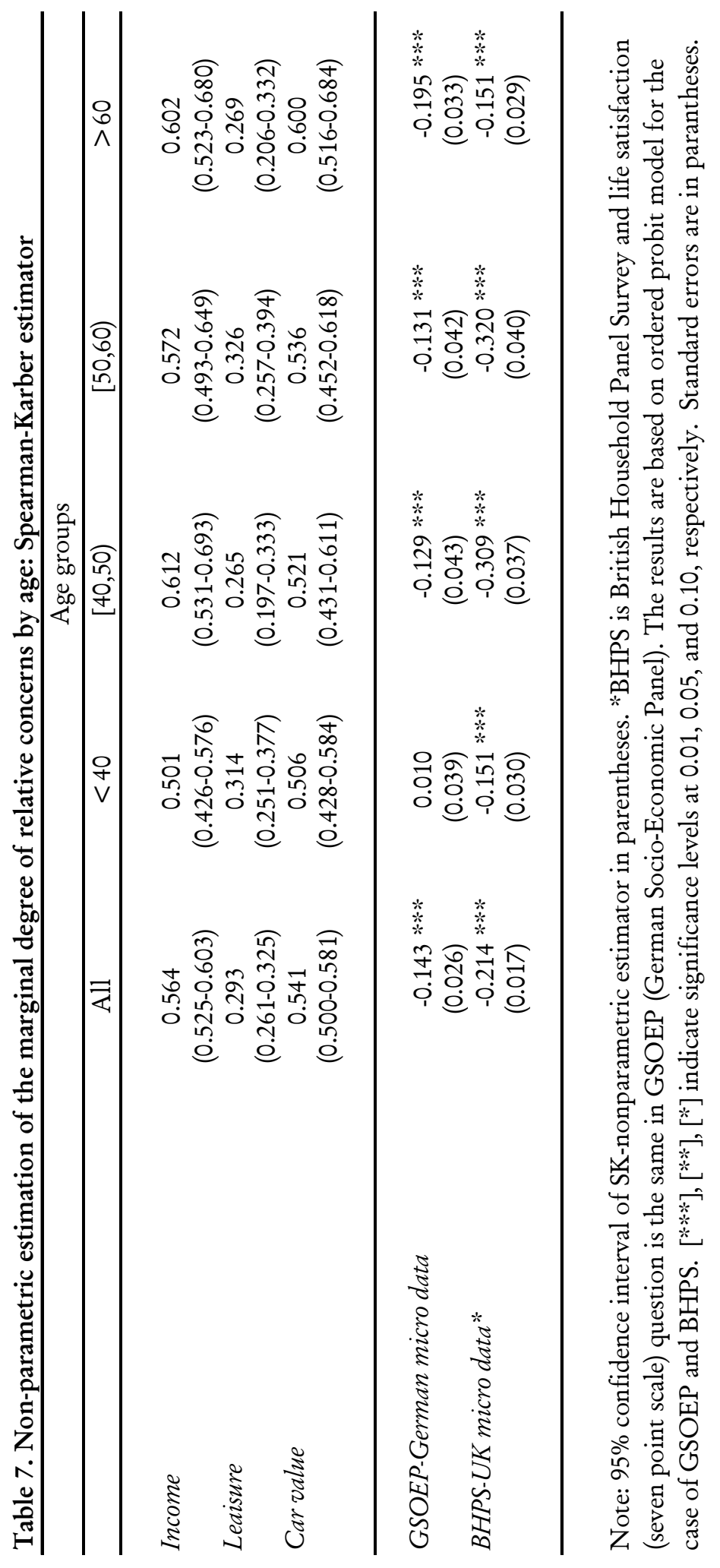




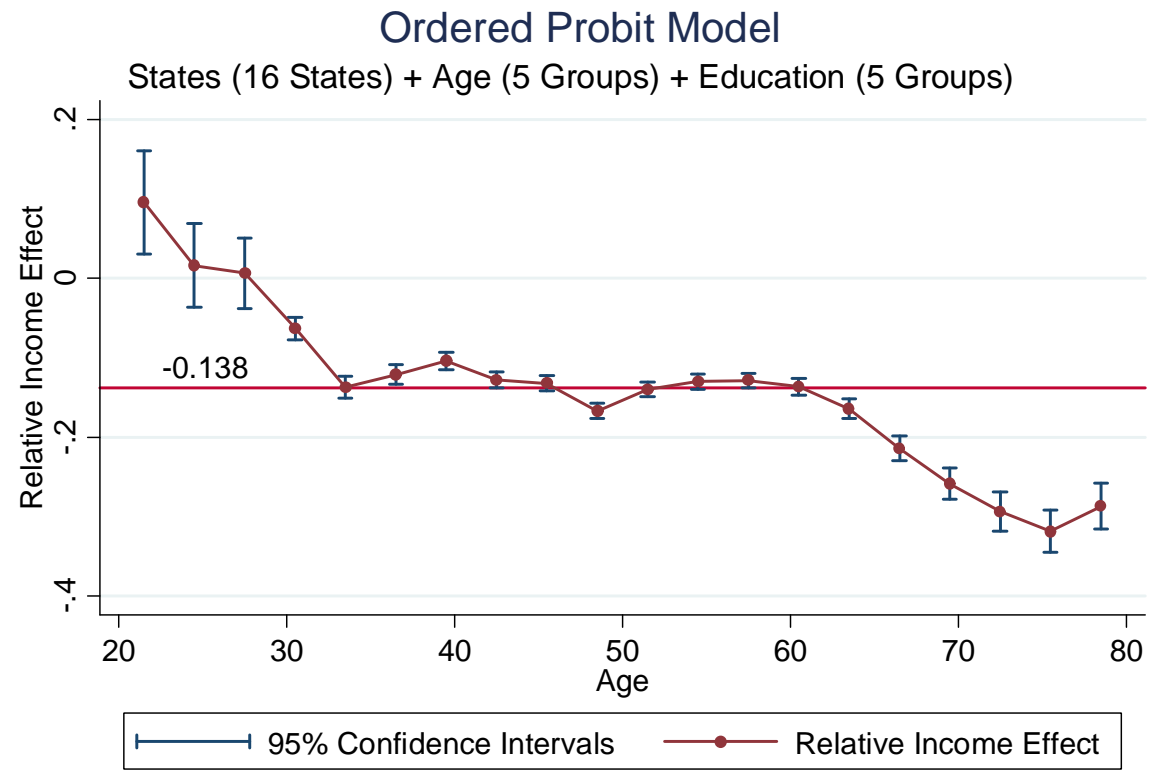

Note: GSOEP, Moving average with window $(-/+3)$ years

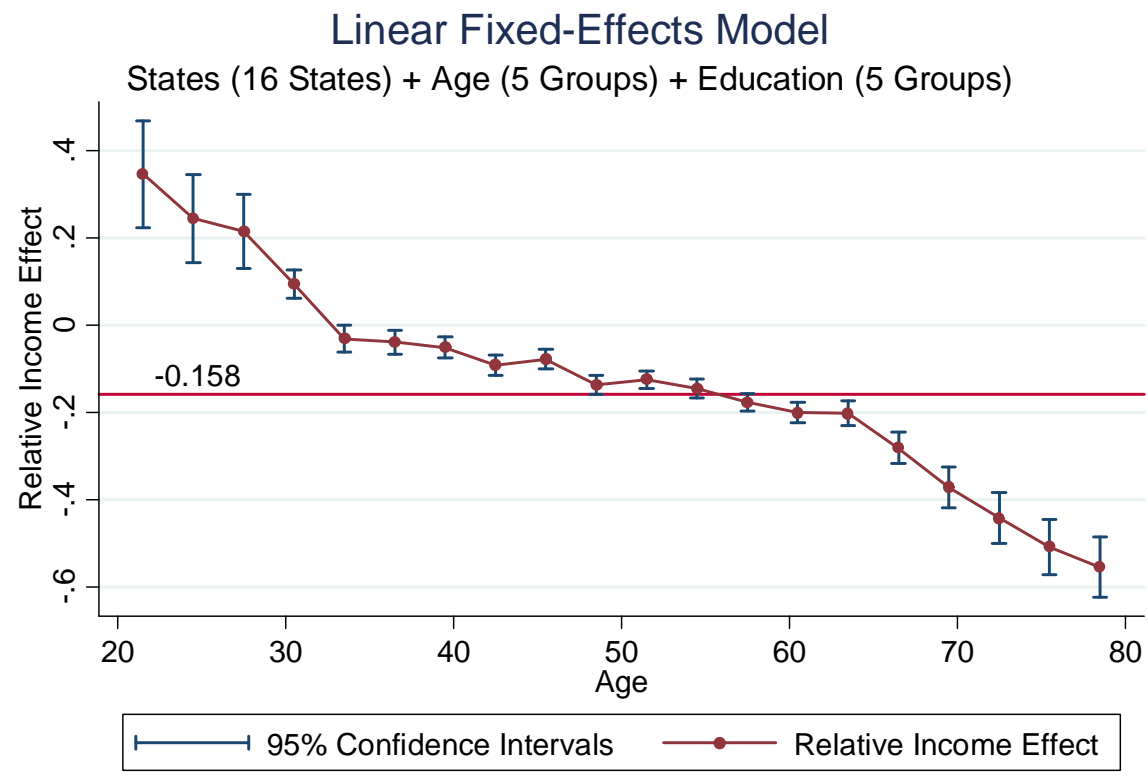

Note: GSOEP, Moving average with window $(-/+3)$ years

Figure 1. Life-cycle patterns of relative income effects. Each point is calculated in 3-year age intervals. The graphics are smoothed using a moving average filter of three years. 


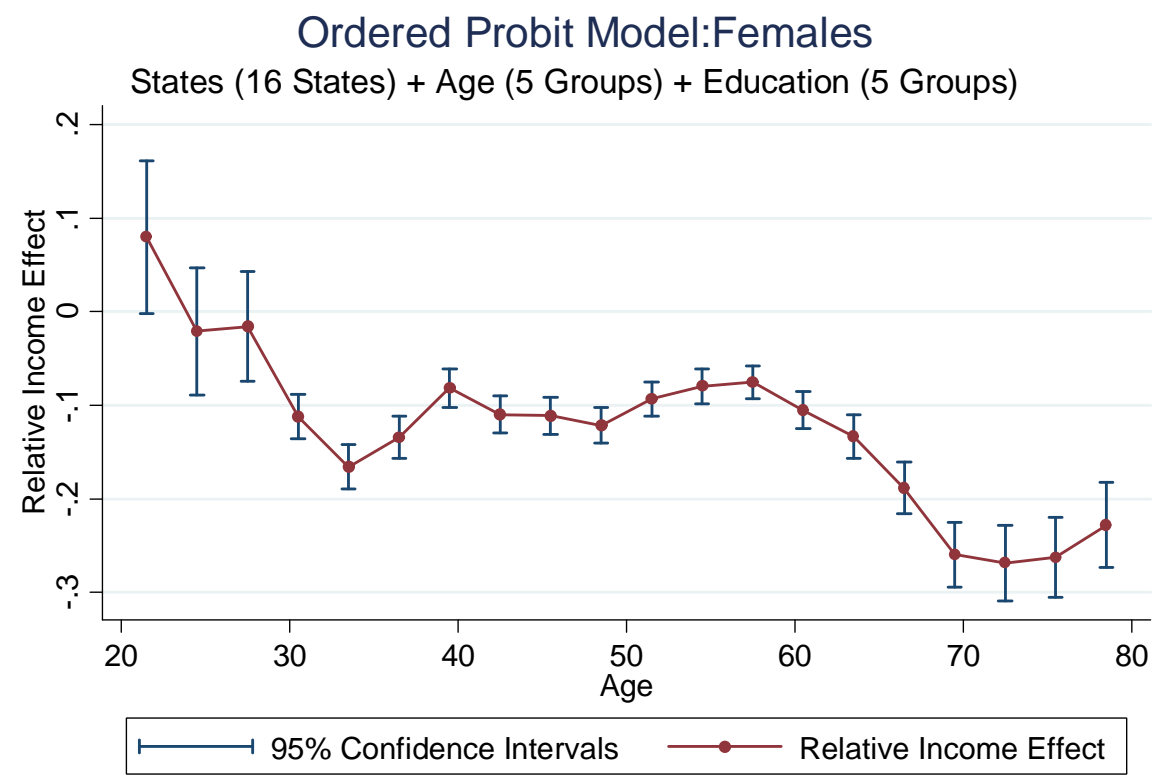

Note: GSOEP, Moving average with window $(-/+3)$ years

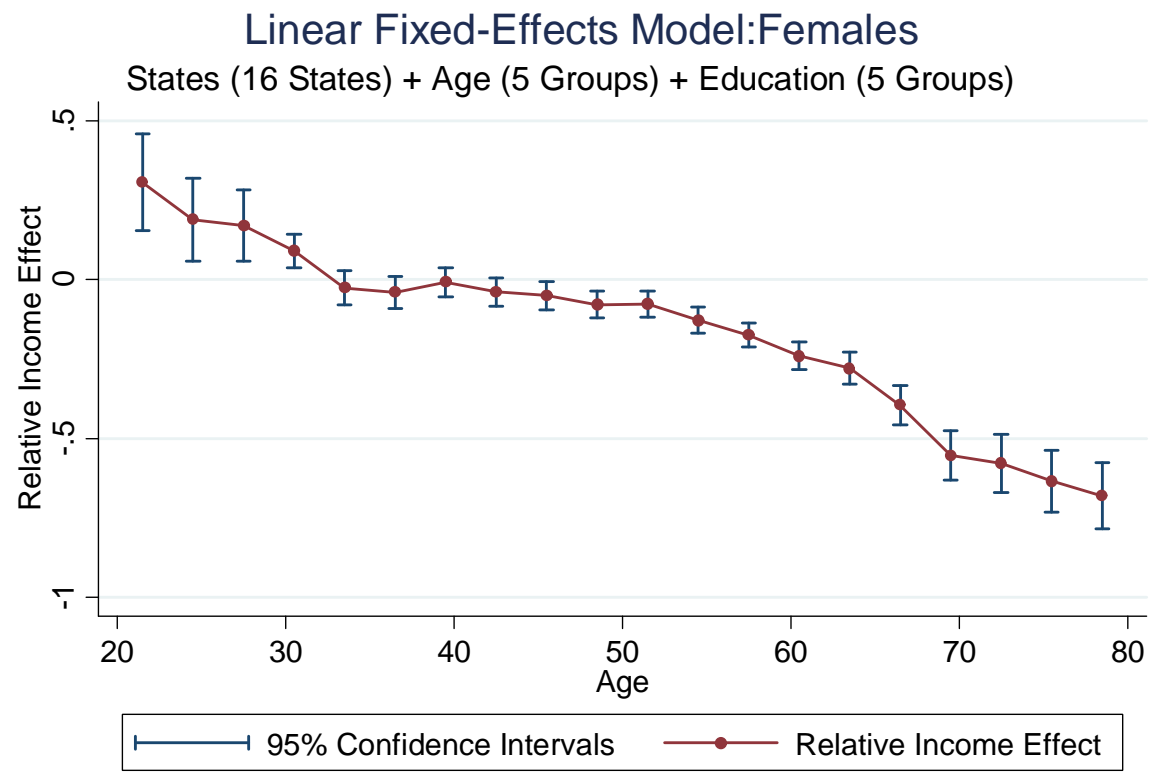

Note: GSOEP, Moving average with window $(-/+3)$ years 


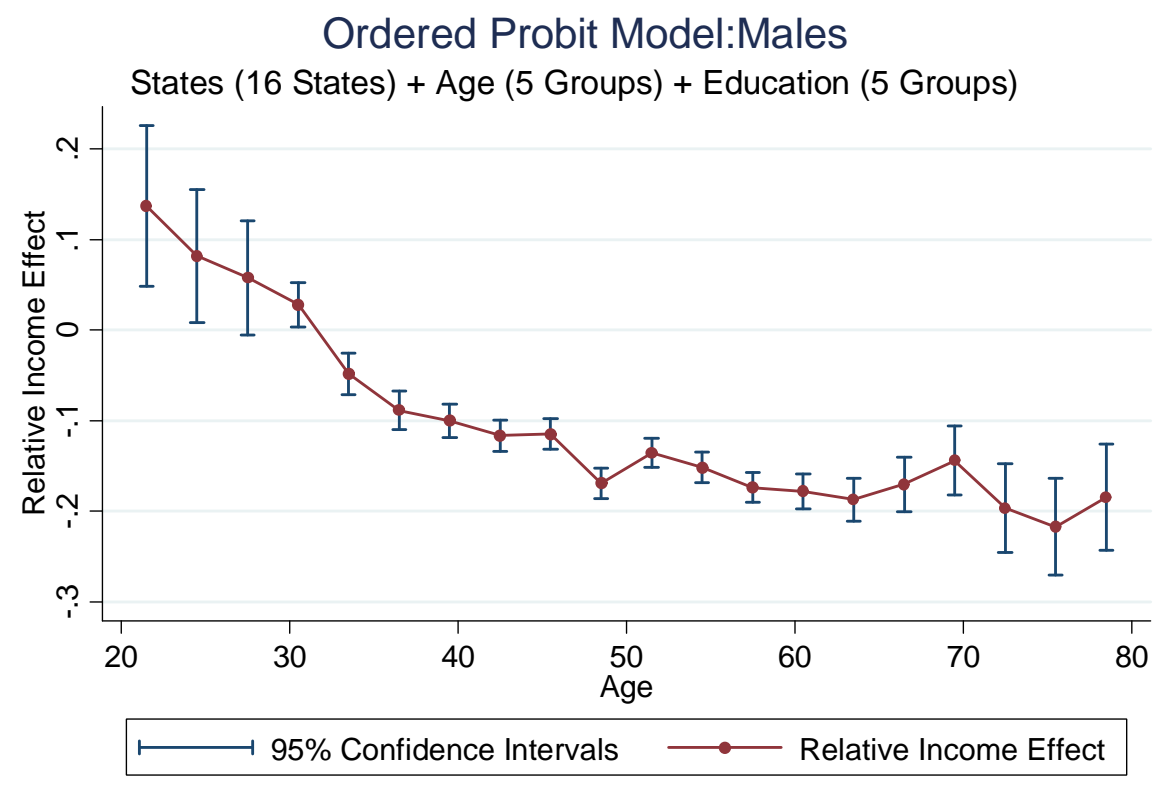

Note: GSOEP, Moving average with window $(-/+3)$ years

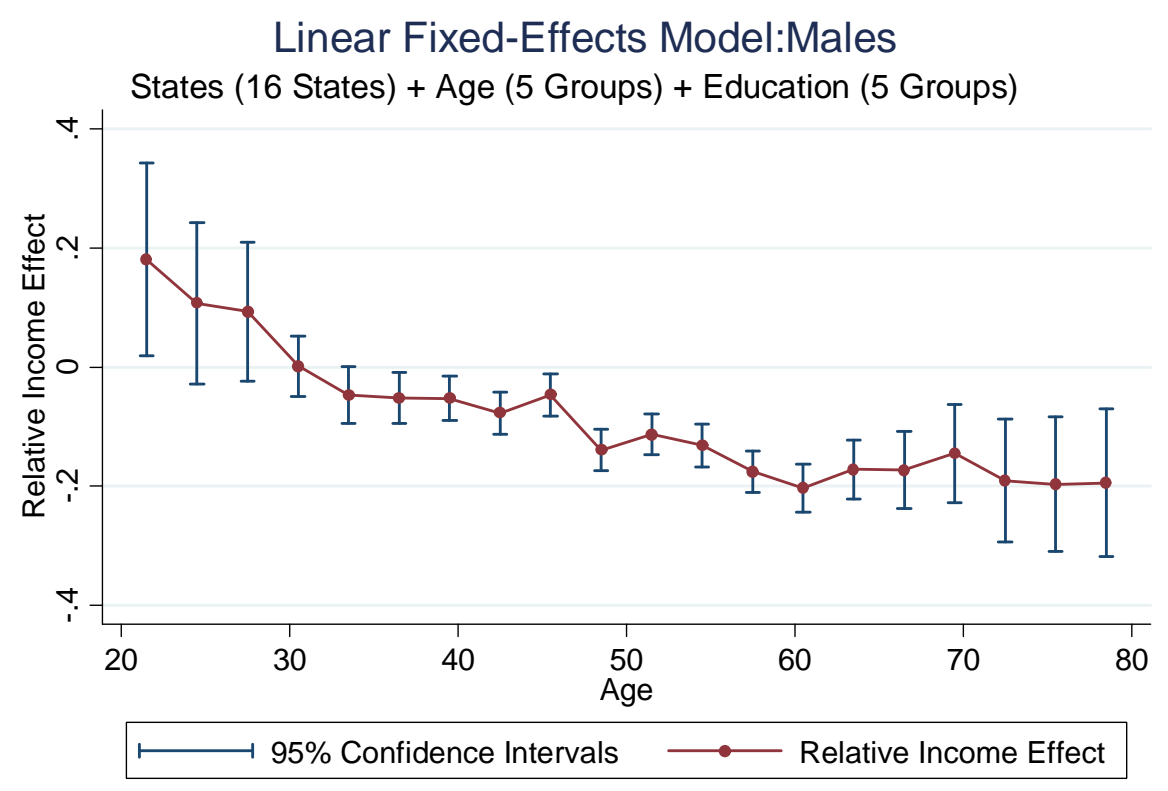

Note: GSOEP, Moving average with window $(-/+3)$ years

Figure 2. Life-cycle patterns of relative income effect by gender. Each point is calculated in 3-year age intervals. The graphics are smoothed using a moving average filter of three years. 


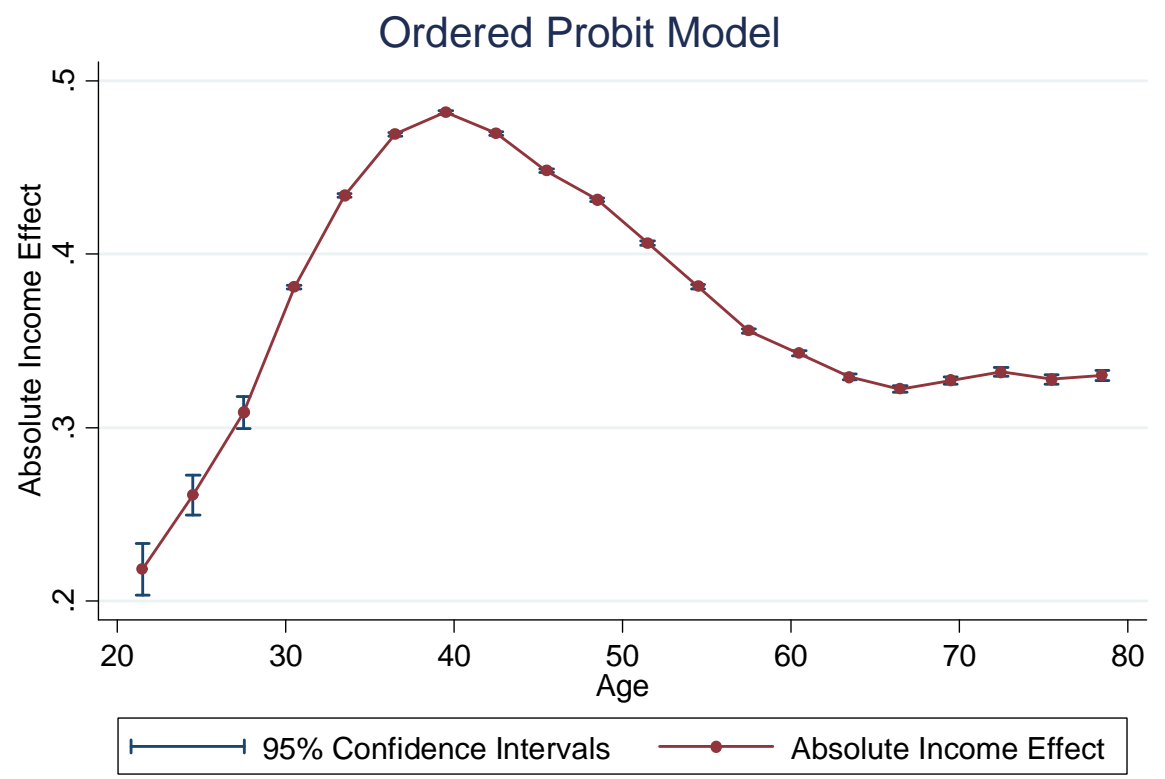

Note: GSOEP, Moving average with window $(-/+3)$ years

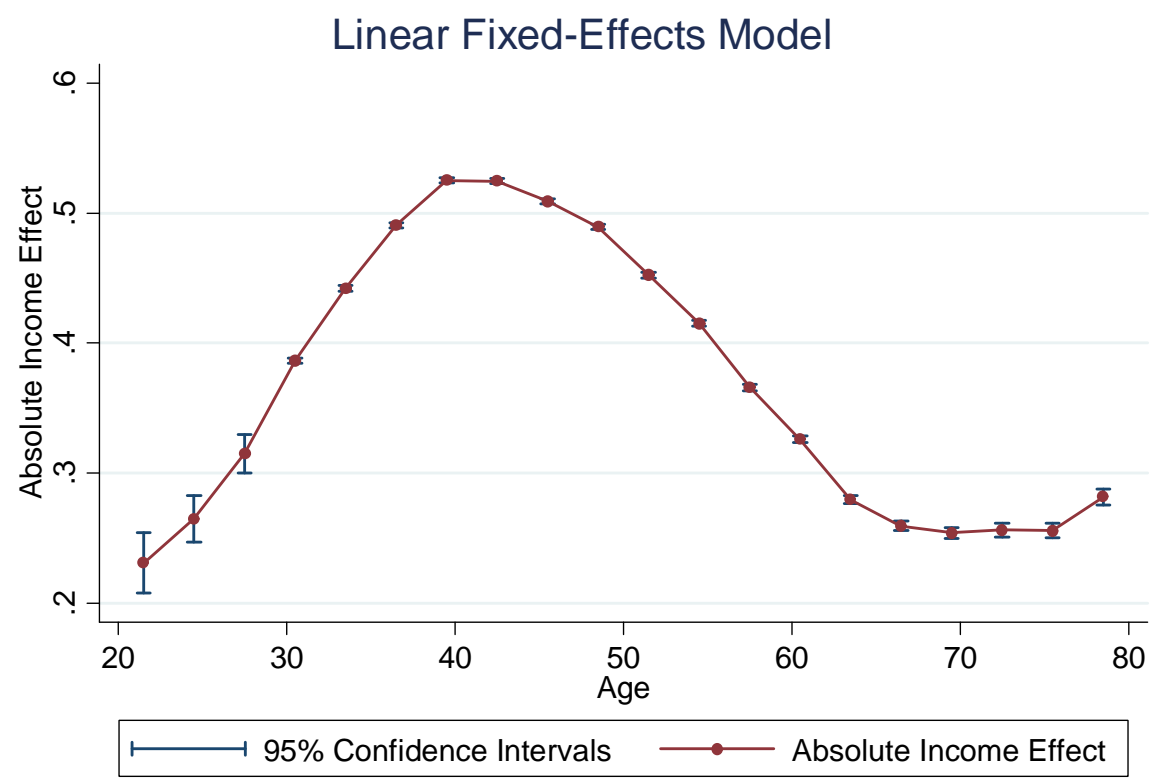

Note: GSOEP, Moving average with window $(-/+3)$ years

Figure 3. Life-cycle patterns of absolute income effect. Each point is calculated in 3-year age intervals. The graphics are smoothed using a moving average filter of three years. 
In this part of the questionnaire we require you to choose which society you consider to be the best one for an imaginary person living two generations into the future. You can, for example, imagine a grandchild, great grandchild or another relative that you are choosing for. By 'best' we mean the society in which your future relative will be most content.

- The difference between the societies is the income level or the amount of consumption for a certain good of your future relative, and the average income and consumption of the society.

- The variety of goods and their prices are the same for both societies. For 100 SEK you can buy the same goods and the same amount in both societies. Prices are expressed in today's price level.

- It is important that you focus your answer on what is in the best interest of the imagined person, and nothing else. There is no "correct" response to these questions and we ask you to reflect on the choices carefully.

\section{Example}

In the example below your future relative earns 2000 SEK more in society A compared with society B. You can also see that your future relative earns $5000 \mathrm{k} /$ month less than the average income in society A and 3000

SEK/month more than the average in society B.

Society A - Your relative's income is $20000 \mathrm{SEK} / \mathrm{month}$ after tax.

- The average income in society is $25000 \mathrm{SEK} /$ month after tax.

Society B

- Your relative's income is $18000 \mathrm{SEK} /$ month after tax.

- The average income in society is $15000 \mathrm{SEK} /$ month after tax.

We require you to choose which society you consider to be the best one for your future relative; that is, the society in which your future relative will be most content. It is important that you focus your answer solely on this; that is: which society is the best for your future relative? You should not consider which society is best on the whole.

Figure 4. Example question in the experiment. 